OPEN ACCESS

Edited by: Andrew Zloza,

Rush University Medical Center,

United States

Reviewed by:

Mauro G. Tognon,

University of Ferrara, Italy

Elena Cherkasova,

National Institutes of Health $(\mathrm{N} / \mathrm{H})$,

United States

Micol Silic-Benussi,

Veneto Institute of Oncology (IRCCS),

Italy

*Correspondence:

Gkikas Magiorkinis

gmagi@med.uoa.gr

${ }^{\dagger}$ These authors have contributed equally to this work

Specialty section:

This article was submitted to

Cancer Molecular Targets

and Therapeutics,

a section of the journal

Frontiers in Oncology

Received: 29 March 2021 Accepted: 12 October 2021 Published: 29 October 2021

Citation:

Kitsou K, lliopoulou M, Spoulou V, Lagiou P and Magiorkinis G (2021)

Viral Causality of Human Cancer and

Potential Roles of Human Endogenous

Retroviruses in the Multi-Omics Era:

An Evolutionary Epidemiology Review.

Front. Oncol. 11:687631.

doi: 10.3389/fonc.2021.687631

\section{Viral Causality of Human Cancer and Potential Roles of Human Endogenous Retroviruses in the Multi-Omics Era: An Evolutionary Epidemiology Review}

\author{
Konstantina Kitsou ${ }^{1,2 \dagger}$, Maria lliopoulou ${ }^{1 \dagger}$, Vana Spoulou ${ }^{2}$, Pagona Lagiou ${ }^{1}$ \\ and Gkikas Magiorkinis ${ }^{1 *}$
}

\begin{abstract}
1 Department of Hygiene, Epidemiology and Medical Statistics, School of Medicine, National and Kapodistrian University of Athens, Athens, Greece, 2 Immunobiology and Vaccinology Research Laboratory, First Department of Peadiatrics, "Aghia Sophia" Children's Hospital, School of Medicine, National and Kapodistrian University of Athens, Athens, Greece
\end{abstract}

Being responsible for almost $12 \%$ of cancers worldwide, viruses are among the oldest known and most prevalent oncogenic agents. The quality of the evidence for the in vivo tumorigenic potential of microorganisms varies, thus accordingly, viruses were classified in 4 evidence-based categories by the International Agency for Research on Cancer in 2009. Since then, our understanding of the role of viruses in cancer has significantly improved, firstly due to the emergence of high throughput sequencing technologies that allowed the "brute-force" recovery of unknown viral genomes. At the same time, multiomics approaches unravelled novel virus-host interactions in stem-cell biology. We now know that viral elements, either exogenous or endogenous, have multiple sometimes conflicting roles in human pathophysiology and the development of cancer. Here we integrate emerging evidence on viral causality in human cancer from basic mechanisms to clinical studies. We analyze viral tumorigenesis under the scope of deep-in-time humanvirus evolutionary relationships and critically comment on the evidence through the eyes of clinical epidemiology, firstly by reviewing recognized oncoviruses and their mechanisms of inducing tumorigenesis, and then by examining the potential role of integrated viruses in our genome in the process of carcinogenesis.

Keywords: evolutionary epidemiology, cancer, viral tumorigenesis, viruses, endogenous retroviruses, Viruses in Human Tumorigenesis

\section{INTRODUCTION}

The pathogenic effect of viruses has led to the misconception that viruses could only be harmful, with scientific research also being oriented in this direction for many years. Viruses can be perceived as evolutionary champions that seem to play a paramount role in human health and disease as underlined by the increasingly developing study field of the mammalian virome (1). Viruses are linked to extensive phenomena of micro-and macro-evolution, developing a wide range of actions characterized by 
commensalism, competition, or parasitism and thus, causing respectively the states of symbiosis or dysbiosis with their host. Oncoviruses, a non-taxonomic group of viruses with research history resembling roller-coaster, have either been considered unrelated or even the main cause of cancer. Although we know that viruses are neither necessary nor sufficient to cause cancer, research has led to linking viruses with the development of cancer and the foundation of cancer biology. To date, the worldwide burden of cancers with viral etiology accounts for almost $12 \%$ of cancer cases - exceeding $20 \%$ in the developing world $(2,3)$. According to the International Agency for Research on Cancer (IARC), seven viruses have been characterized as Group 1 carcinogens for humans but their part in cancer pathogenesis seems to vary among different viruses and different disease forms $(4,5)$. The seven carcinogenic viruses along with their route of transmission and their associated malignancies are summarized in Table 1. Carcinogenesis is a multi-casual and multi-stage process and viruses, whether active or in latency, seem to act directly, indirectly, and synergistically with multiple co-factors towards the induction of cancer's hallmarks. While tumorigenesis might be seen as an underachieved adaptation, the preservation of oncoproteins in tumor-viruses, as demonstrated by phylogenetic analyses, suggests the evolutionary advantages of viruses as life forms and the coevolutionary dynamics in the virus-host interaction during chronic infection leading to carcinogenesis.

Human studies focusing on the unequal distribution of viruses between cases and control subjects constitute the cornerstone for initial research and have been widely reviewed. Disentangling between cause and effect following these epidemiological observations remains a challenge, one that can be supported by the revolution of high throughput molecular technologies. The first step in the era of -omics was made with the development of genomics, whose roots reside in DNA sequencing and already counts three generations, the latest two known as High Throughput Sequencing (HTS) technologies. HTS allowed the design and successful completion of large-scale cancer genomics projects like the Cancer Genome Atlas and the International Cancer Genome Consortium recording for the first time a detailed list of mutations from tumors and cancer cell lines (6). The development of HTS has provided a more detailed perspective on the understanding of the virus-cancer link, concerning viral types and geographic prevalence of viruses and related malignancies.

Transcriptomic data capture a more dynamic picture and improve the current understanding of many fundamental viralhost pathophysiological processes, including expression of repetitive elements, such as Human Endogenous Retroviruses (HERVs), whose potential implication in human cancer will be examined later in this review. The development of metagenomics widely enables and facilitates the detection of novel viruses, by utilizing sequence information from known pathogens to identify related and still undiscovered agents in samples (7). Of note, metagenomic pipelines have been designed for the detection of viral species and quantification of their gene

TABLE 1 | Summary of the viruses classified as Group 1 carcinogens for humans according to the IARC, route of transmission and associated malignancies.

\begin{tabular}{|c|c|c|c|}
\hline Virus & $\begin{array}{l}\text { Genetic } \\
\text { Material }\end{array}$ & Route of Transmission & Associated Cancer Types \\
\hline EBV & dsDNA & Oral transmission via saliva, transfusion (reported) & $\begin{array}{l}\text { Burkitt lymphoma, classic Hodgkin's lymphoma (especially mixed-cellular subtypes), } \\
\text { Lymphomas in immunosuppressed individuals (post-transplant and HIV-associated } \\
\text { lymphoproliferative disorders), Extra-nodal Natural Killer/T-cell lymphoma (nasal type), } \\
\text { Nasopharyngeal carcinoma, Gastric cancer (LD), Diffuse large B-cell lymphoma of the elderly } \\
\text { (LD), Lymphoepithelioma-like carcinoma (LD) }\end{array}$ \\
\hline HBV & $\begin{array}{l}\text { partially } \\
\text { dsDNA }\end{array}$ & $\begin{array}{l}\text { Percutaneous and permucosal exposure to } \\
\text { infected body fluids, sexual contact, blood and } \\
\text { blood product transfusion, solid organ } \\
\text { transplantation from an infected donor, unsafe } \\
\text { needle practices, vertical transmission }\end{array}$ & $\begin{array}{l}\text { Hepatocellular carcinoma, Cholangiocarcinoma (LD), Hodgkin's lymphoma (LD), non- } \\
\text { Hodgkin's lymphoma (LD), Pancreatic Carcinoma (LD) }\end{array}$ \\
\hline $\mathrm{HCV}$ & $\operatorname{ssRNA}(+)$ & $\begin{array}{l}\text { Blood and blood product transfusion, solid organ } \\
\text { transplantation from an infected donor, unsafe } \\
\text { needle practices, perinatal and sexual transmission } \\
\text { (less effectively) }\end{array}$ & $\begin{array}{l}\text { Hepatocellular carcinoma, non-Hodgkin's lymphoma (especially B-cell), Biliary tract and } \\
\text { Gallbladder carcinoma (LD), Myeloid Leukemia (LD), Thyroid carcinoma (LD) }\end{array}$ \\
\hline $\mathrm{HHV}-8$ & dsDNA & $\begin{array}{l}\text { Oral transmission via saliva, parenteral transmission } \\
\text { (possible), transplantation (reported) }\end{array}$ & Kaposi's sarcoma, Primary effusion lymphoma, Multicenter Castleman's Disease \\
\hline HPV & dsDNA & $\begin{array}{l}\text { Skin-to-skin contact, skin-to-mucosa contact, } \\
\text { perinatal transmission (rare) }\end{array}$ & $\begin{array}{l}\text { Cervical Cancer (HPV:16,18, 31,33,35,39,45,51,52,56,58,59), HPV16: cancer of the vulva, } \\
\text { vagina, penis and anus, oral cancer, oropharyngeal carcinoma, tonsillar carcinoma, cancer of } \\
\text { the larynx }\end{array}$ \\
\hline MCPyV & dsDNA & Skin contact (Not clarified) & Merkel Cell Carcinoma, chronic lymphocytic leukemia (reported) \\
\hline HTLV-1 & $\operatorname{ssRNA}(+)$ & $\begin{array}{l}\text { Sexual transmission, vertical transmission (mostly } \\
\text { through breastfeeding), transfusion of cellular blood } \\
\text { products, unsafe needle practices (rare) }\end{array}$ & Adult T-cell leukemia/lymphoma \\
\hline HIV-1 & $\operatorname{ssRNA}(+)$ & $\begin{array}{l}\text { Sexual transmission, parenteral transmission (blood } \\
\text { and blood product transfusion, unsafe needle } \\
\text { practices), vertical transmission (placental, child } \\
\text { delivery, breastfeeding) }\end{array}$ & $\begin{array}{l}\text { Kaposi's sarcoma, non-Hodgkin lymphoma, Hodgkin's lymphoma, Cervical and anogenital } \\
\text { carcinoma, Cancer of the conjunctiva, Cancer of the vulva, vagina, and penis (LD), Skin } \\
\text { carcinoma (LD), Lung and Hepatocellular carcinoma (LD) }\end{array}$ \\
\hline
\end{tabular}

"IARC monographs on the evaluation of carcinogenic risks to humans, volume $100 \mathrm{~B}$, biological agents" (4) is the source of the information in this table. LD, Limited Data. 
expression in tumors (8). Epigenomics fills the gap between genomic and transcriptomic and enables the identification of histone modifications catalyzed by acetylation, methylation, and phosphorylation and thus regulate transcription (9).

Thus, the rapid development of HTS technologies in the last decade has enabled the elucidation of multiple mechanisms with which viruses, both exogenous and endogenous, can contribute to the induction of genomic instability to their host and subsequently the development of malignancy. Here, we will firstly focus on the importance of -omics mechanistic studies in elucidating lesser-known mechanisms of viral tumorigenesis while addressing chosen examples of their application and we will discuss the evolutionary implications arising from ongoing research in the human-virus multi-omics research arena regarding recognized carcinogenic viruses. Finally, we will focus on the evolutionary relationship between humans and HERVs, evidence of the potential role of HERVs in human cancer development, and a variety of tumorigenic mechanisms they appear to employ.

\section{MULTI-OMICS IN THE STUDY OF MECHANISMS OF TUMORIGENESIS OF WELL-ESTABLISHED ONCOVIRUSES}

In this first part of our manuscript, we aim to revisit selected examples of mechanisms by which the seven IARC recognized oncoviruses contribute to the development of malignancy in humans.

\section{Epstein-Barr Virus}

Concerning the evolutionary aspects of Group 1 tumorigenic viruses, Epstein-Barr Virus (EBV) provides us with an example of human-virus evolutionary conflict. Several EBV microRNAs (miRNAs) have been conserved across $\geq 13$ million years in the Lymphocryptovirus genus, a member of the Herpesviridae family (10), possibly due to a "stealth" advantage they offer over the host's immune reaction (11). Furthermore, circular RNAs (circRNAs), with not yet clarified functions seem to be preserved through functional homologs among lymphocryptoviruses and appear to play an important role in viral biology, the persistence of infection, and latency stage as well as virus-associated malignancy development (12). Interestingly, EBV circular BamHI A rightward transcripts (circBARTs) were linked to latency in EBVrelated tumors including post-transplant lymphoproliferative disease (13) (Figure 1).

HTS offered a detailed understanding of the variability of different EBV strains and their geographic distribution (14) explaining the subsequent differences in the geographical distribution of endemic EBV-associated malignancies (15). HTS has enabled the recognition of numerous EBV strains and allowed a detailed understanding of the differences between type 1 and type 2 strains, the most widely used classification for EBV strains (16). Epstein-Barr Nuclear Antigen-2 (EBNA-2) is the main source of sequence variation between type 1 and type 2 strains of EBV, but HTS approaches recently recognized SNPs located in the EBNA-3 viral gene as well as in its nearby gp350 and gp42 viral genes (16). The recognition of further disctinctive characteristics between type 1 and type 2 strains could be proven

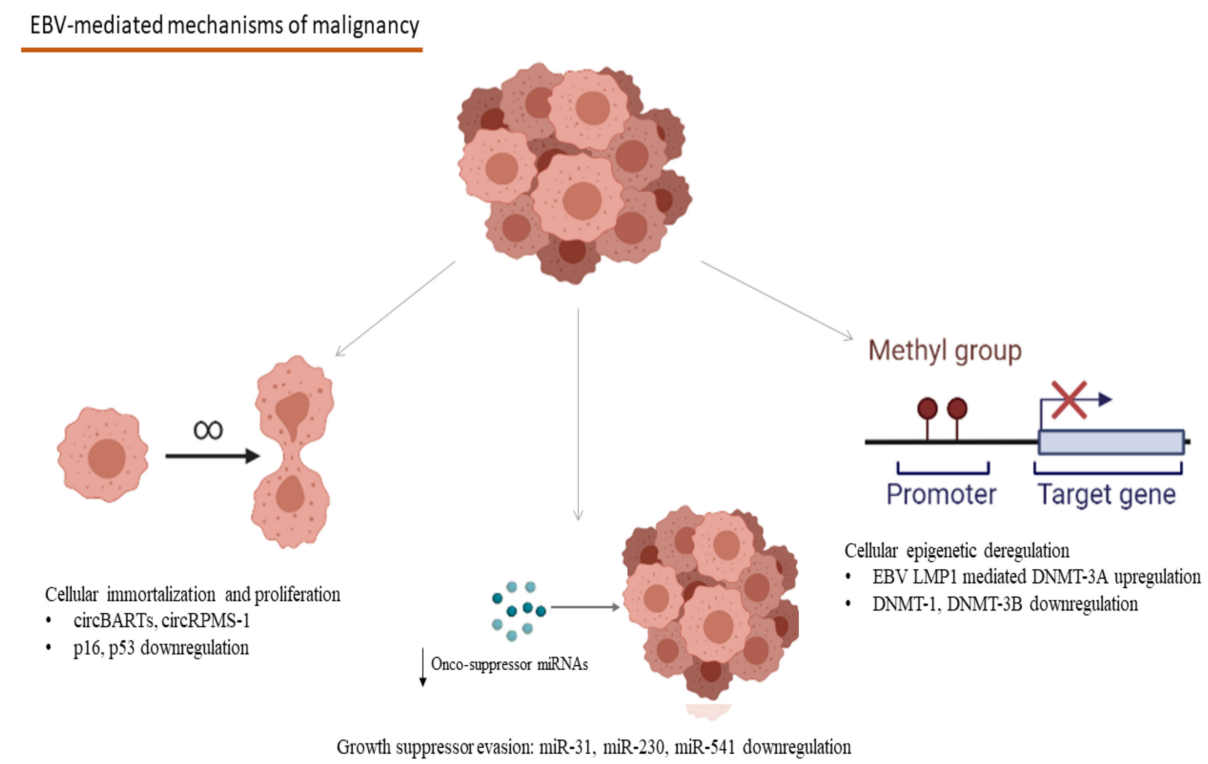

FIGURE 1 | Mechanisms involved in the EBV-associated carcinogenesis: CircBARTs and circRPMS1 are implicated in the cellular immortalization and the induction of uncontrolled proliferation. CircRPMS1 is negatively correlated to the expression of innate oncosuppressor miRNAs (miR-31, miR-230 and miR-541), as observed in NPC. Gene expression modification takes place in B-cell malignancies, as a result of the methylation pattern-modifications caused by the EBV infection through the EBV LMP1 mediated upregulation of DNMT-3A and the downregulation of DNMT-1 and DNMT-3B (EBV, Epstein-Barr Virus; circBARTs, circular BamHI A rightward transcripts; miRNAs, microRNAs; NPC, Nasopharyngeal Carcinoma; EBV LMP1, EBV latent membrane protein 1; DNMT, DNA methyltranserase). Created in BioRender.com. 
useful in the disambiguation of the exact mechanisms by which type 2 strains lead to decreased B-cell growth and transformation, reducing its malignant dynamics compared to type 1 strains.

Multi-omics studies have unraveled EBV's central role in the pathogenesis of Natural Killer/T-Cell Lymphomas (NK/T lymphomas) and Nasopharyngeal Carcinoma (NPC) (17). More specifically, EBNA-1 derived from NPC tumors demonstrated reduced function in the preservation of latency by failing to maintain episomal integrity and thus to suppress the EBV lytic cycle at an epigenetic level (17). Methylation modification seems to take place after the EBV infection of gastric epithelia too, leading to anomalies in enhancer and promoter activity of multiple host genes, which have been observed both in vitro and in vivo, in EBV-positive gastric malignancies (18). The modifications described in this study were linked to hallmarks of carcinogenesis, including angiogenesis, inflammation, cell migration dynamics, uncontrolled proliferation, and evasion of apoptosis (18). In the case of EBV-related hematologic malignancies, after B-cell infection, EBV remains latent in the germinal centers of secondary lymphoid tissues, and mostly in memory B-cells, where EBV infection appears to affect cellular methylation patterns and has been linked to distinct gene expression profiles (19). EBV infection causes deregulation in the expression of DNA methyltransferases with the upregulation of DNMT3A and downregulation of DNMT3B and DNMT1 (19). More specifically, the upregulation of DNMT3A is mediated through the EBV latent membrane protein 1 (EBV LMP1) oncogene, one that plays a crucial role in the development of Hodgkin's Lymphoma and the methylation modifications caused in the host's genome demonstrated a specific pattern, rather than a random distribution, creating specific epigenetic signatures (19) (Figure 1). Furthermore, a crucial expressional modification in the process of EBV-related carcinogenesis is the interference of EBV antigens with the regulation of cornerstone proteins in the human cell antitumor defense, like p16 and p53 (20-22). The relation between EBV antigens and these proteins has been extensively studied in B-cell lymphomas like Hodgkin lymphoma, where EBV-mediated downregulation of p16 and p53 has been linked to lymphoblastic proliferation (20-22) (Figure 1). The role of epigenetic involvement in the EBVrelated carcinogenesis makes epigenetic inhibitors a promising candidate in treating EBV-associated malignancies both in vitro and in vivo in an animal study with a model of NPC in mice (23).

Despite the unquestionable value of proteomic approaches, they do not appear to be a proper or sufficient approach for the elucidation of the EBV-related carcinogenesis due to the great variety of the pathological events involved in tumorigenesis related to this virus (24). Comparative proteomics is a layout commonly used in this case in order either to compare proteome in different cycles and stages of infection (25) or even to compare proteomes of cell lines infected with other herpesviruses (26). Clarification of virus-related immunogenomic features of various tumors could facilitate the development of immunotherapy by targeting virus or virus-induced proteins that could sustain a feasible therapeutic target.

\section{Kaposi Sarcoma Herpesvirus/ Human Herpesvirus-8}

Kaposi Sarcoma Herpesvirus/Human Herpesvirus-8 (KSHV/ HHV-8) appears to be a slowly evolving virus with a substitution rate estimated at $6.42 \times 10^{-4}$ substitution/site/year and a low mutation rate comparable to othe double stranded DNA viruses, lower than RNA viruses (27-29). This fact however could be altered as a result of the increase in Human Immunodeficiency Virus (HIV) prevalence that led to a subsequent Kaposi Sarcoma (KS) epidemic (30). Despite the emergence of KSHV/HHV-8 malignancies in the setting of the HIV epidemic, non-HIVrelated KS, despite rare (31), underscores the role of the hosts' innate characteristics along with their immune condition in the KS development.

HTS technologies have aided the elucidation of the multiple mechanisms by which KSHV/HHV-8 leads to either KS or Blymphoproliferative malignancies, i.e. Primary Effusion Lymphoma (PEL) and the plasmablastic variant of multicentric Castleman's disease (MCD). Alike EBV, viral cirRNAs are expressed in PEL cell lines and appear to play an important role in the process of carcinogenesis induced by DNA viruses (13). The presence of HHV-8/KSHV encoded circRNA from the vIRF4 viral locus (circvIRF4) as well as RNase-R resistant Polyadenylated Nuclear (circPAN) has been recognized in $\mathrm{HHV}-8 / \mathrm{KSHV}$ infected PEL cells (13). Interestingly, RNase Rresistant circvIRF4 has been recognized in latent PEL cells (13). Conversely, the expression of circPANs is upregulated during HHV-8/KSHV lytic replication (32). The exact mechanisms by which circRNAs encoded by $\mathrm{HHV}-8 / \mathrm{KSHV}$ result in the development of the hallmarks of cancer is still little understood. Bearing in mind the disruption mediated by vIRF4 in the p53 and Notch pathways (33) and the effect of long noncoding PAN on angiogenenesis (34), it is reasonable to assume a potential regulatory function of this noncoding RNA on those pathways.

Furthermore, virally encoded proteins, like Latency Associated Nuclear Antigens, viral Interleukin-6, viral chemokines, viral cyclin, and Kaposins have been associated with the balance between lytic and latent phases of the infection and most importantly with the induction of malignancy hallmarks in the KSHV/HHV-8-associated malignancies $(35,36)$. In RNA-seq analyses accompanied by methylation studies, KSHV/HHV-8 has been shown to promote initially hypermethylation followed by slower hypomethylation in many genomic sites in PEL (37). Three hypomethylated promoters were recognized that led to the subsequent upregulation of Mucin-13 (MUC13), Galectin1 (LGALS1), and Protocadherin Beta-5 (PCDHB5) genes in PEL cells (37). Increased expression of MUC13 and PCDHB5 have been correlated to epithelial tumors (38-40) and most interestingly, Galectin-1, encoded by LGALS1 participates in the malignant transformation and metastasis of many tumors and was correlated to neoangiogenesis and cancer development in animal models of KS (37). Intriguingly in the same study, the in vitro treatment of PEL cells with demethylating agents was shown to slow down cellular growth offering a potential therapeutic target for this KSHV/HHV-8-associated malignancy (37). 
Furthermore, unfolding the intracellular trafficking of K15, an HHV-8 kaposin mainly expressed during the lytic cycle, could assist pharmaceutical research by elucidating the various integration sites corresponding to the lytic or latent cycle and thus provide the opportunity of specifically targeting integration sites $(41,42)$.

\section{Hepatitis-B Virus}

Data emerging from sea depths from a family of non-enveloped Hepatitis B Virus (HBV)-related fish viruses indicates that the evolutionary history of hepadnaviruses is older than 400 mya (43). Paleovirological samples verify that HBV infected humans at least 7000 years ago (44). Intriguingly, the exact evolution of HBV over time is still unclear as an HBV sample isolated from a mummy of the 16th century was found to be closely related to modern type D HBV and thus the molecular-clock method for the estimation of $\mathrm{HBV}$ origin cannot be utilized, until more ancient paleovirological samples become available and aid to the better comprehension of HBV-human co-evolution (45).

Genomics studies have pointed to the crucial role of the integration profile of viruses in the determination of the cell evolution towards malignancy and the prognosis of certain types of cancer. In the case of HBV-related Hepatocellular Carcinoma (HCC), increased viral DNA integrations and elevated viral load has been linked to the development from chronic hepatitis to HCC (46). Also, HCC tissues demonstrate a significantly higher number of HBV DNA integrations in comparison to tissues derived from the rest of the $\mathrm{HBV}$-infected liver tissues, a difference that could also be detected at a transcriptional level (46). Furthermore, the HBV integration sites are characterized by chromosomal instability, a milestone in the cellular induction of cancer (47). Genomics studies on human Tumor Necrosis Factor $\alpha$ have linked certain polymorphisms to increased HBVrelated HCC susceptibility, underlining the importance of the hosts' intrinsic characteristics on the human-virus interactions (48). Recently, increased expression of the Small Protein of the HBV Surface Antigen has been linked to aberrant transcription factors production, leading to unfavorable prognosis, as it has been linked to increased cell migration and metastatic dynamics, and targeting its expression may offer improvement of survival potentials (49). HBV short mRNAs expressed by HBVassociated HCC were found to produce epitopes that can be recognized by HBV-specific B-cells (50). Autologous T-cells were engineered to express T-cell Receptors specific for these HBVencoded epitopes and were administered to two patients with metastatic HBV-associated HCC and resulted in the decreased size of their lung metastases (50). These HTS based advancements offer very promising novel therapeutic options for virus-induced malignancies. Methylation mechanisms also sustain possible therapeutic targets for $\mathrm{HBV}$-related liver malignancies. A recent meta-analysis, which examined the methylation modification patterns in $\mathrm{HBV}$-related $\mathrm{HCC}$ patients in comparison to $\mathrm{HBV}$-negative $\mathrm{HCC}$ revealed hypermethylation in multiple genes, that was correlated to the HBV infection (51). Interestingly, one of those genes (GSTP1) is hypermethylated, not only in HBV-positive HCC tissues but also in the adjacent $\mathrm{HBV}$-infected liver tissues, a fact that underlines the effect of the viral trigger itself in the methylation pattern modifications that characterize HCC (51). Furthermore, these methylation patterns appear to have different geographical distributions which may indicate the effect of differences in the usual HBV genotypes per location (51). Moreover, methylation of HBV's covalently closed circular DNA is a potential antiviral target, as it was found to markedly reduce viral gene transcription and genome replication, leading to the promotion and maintenance of chronic infection (52).

The implementation of the HBV vaccine in the National Vaccination Schedules of multiple countries shows promising results in terms of HCC prevention and the incidence of HCC has been reduced $(53,54)$. Impressive reduction in the incidence and mortality of HCC have been reported in Taiwan, and similar effects are expected to occur in the countries were populationwide $\mathrm{HBV}$ vaccinations have been established (55). The importance of the HBV vaccination is underscored by the fact that new chronic HBV infections have been associated with vertical transmissions and incomplete vaccination in the affected individuals (56). Additionally, with the increase in the frequency of the initiation at birth of the HBV vaccination, the incidence of chronic HBV infections is expected to decrease in the future and thus HCC cancer incidence (53).

\section{Hepatitis-C Virus}

The hypothesis of the zoonotic origin of Hepatitis-C Virus (HCV) remains debatable. The tendency of viral variants to infect and replicate into hepatic cells to avoid immune responses to the detriment of hepatic tissue is predominant among viruses in the genus of hepacivirus that can establish chronicity (57). A wide range of studies focuses on E1 and E2 envelope glycoproteins which are responsible for its fusion process (58). Although the exact mechanism remains unknown, accumulating evidence suggests some degree of molecular coevolution among those glycoproteins to achieve both the viral fusion to the host's cell and immune evasion (59).

RNA-sequencing analyses elucidated innate immunity responses, regarding type I interferon expression and inflammatory signatures unriddling immune mechanisms of spontaneous resolution of $\mathrm{HCV}$ infection (60). The exact mechanisms by which HCV-related liver cirrhosis in the frames of chronic HCV infection participates in the development of HCC are largely unknown. Recent in vitro evidence suggests that signal transducer and activator of transcription 3 (STAT-3) activation and subsequent transcriptional regulation promotes cell survival in $\mathrm{HCV}$-related cirrhosis, providing the potential median link in the process of HCC following cirrhosis in HCV chronic infection (61).

Moreover, HCV exploits DNA methyltransferases to downregulate onco-suppressing genes resulting in cell cycle acceleration and consequently in the production of more viral particles leading to more extensive $\mathrm{HCV}$-related liver damage (62), which could even directly be connected to cell transformation to malignant. On the other hand, HCV-related HCC is characterized by a distinct genome-wide gene enrichment profile, that does not correlate to viral copy burden but rather to genomic hypomethylation (63). 


\section{Human Papillomavirus}

Papillomaviruses infect both humans and animals, with recent identification in fish implying an origin of $500 \mathrm{My}$ ago (64). Human Papillomavirus (HPV) escapes immune with intraepithelial life cycles, lack of viremia during the infection and cell lysis, and low levels of viral protein expression (65). Unique epithelial tropisms of various HPV subtypes are linked to the host's evolutionary acquisitions, like loss of fur (66). A phylogenetic analysis of Alphapapillomavirus revealed mutations of E6 and E7 facilitating the generation of lower-risk genotypes, a transition favored in the frameworks of viral adaptation and survival, with well-preserved regions being associated with highrisk subtypes, underscoring the role of these well-preserved regions in the processes of tumorigenesis (67).

Regarding the use of HTS in clinical practice and decision making, HTS has elucidated the role of specific viral subtypes in the risk of developing epithelial cancers and markedly contributed to the classification of HPV subtypes as high-risk and low-risk HPVs (68). One of the most important mechanisms by which HPV promotes carcinogenesis is the interference of the E6 and E7 endogenous viral proteins with the epithelial cell apoptosis, immortalization, and consequent genomic stability and inflammatory angiogenesis, through inactivation of p53, retinoblastoma protein, and inflammatory cytokine induction like Interleukin-8 (69). Aside from the viral malignant potential, the hosts' genetic background is a very important component influencing the malignant dynamics of viruses as differences in skin virome between healthy subjects and patients with Dedicator of cytokinesis-8 (DOCK-8) deficiency, a rare primary immunodeficiency characterized by reduced lymphocyte-mediated immunity in collagen-rich tissues leads to proneness to infections, atopy and HPV-related squamous cell malignancies (70).

HPV DNA methylation can be considered a hallmark of the shift from HPV infection to pre-cancer and thus methylation assays show promising results as potential diagnostic tools for the recognition of women with high-grade premalignant cervical lesions/cervical squamous intraepithelial neoplasia, and these methylation modifications are considered as hallmarks of the transition of HPV-infected epithelium to cervical pre-cancer and subsequently cancer (71). Strong associations were described for alpha-7 genotypes of HPV, an observation that underlines the viral susceptibility to these patterns and the development of malignancy (71). Proteomics approaches have also been utilized to identify differential biomarkers in HPV-infected cancer cells in cervical and head and neck cell lines $(72,73)$.

Currently, three types of HPV vaccines are available, a bivalent, against HPV16 and 18 - a quadrivalent, against HPV6, 11, 16, and 18 - and most recently a nonavalent, which offers coverage against HPV6, 11, 16, 18, 31, 33, 45, 52 and 58 (74-76). To date, available data on the implementation of vaccination programs against carcinogenic HPV types 16 and 18 , show that vaccination programs have led to significant reductions in the incidence of HPV-related cervical lesions, including high-grade squamous cell intraepithelial lesions, squamous cell carcinoma, and adenocarcinoma in situ, and vulvar cancer and pre-cancer (77-80). Furthermore, smaller reductions in the incidence of cervical lesions have been reported in unvaccinated women as well, indicating possibly an effect of herd immunity due to overall reductions in carcinogenic HPV infections in the community (81). In the era of the implementation of HPV vaccinations, when the elimination of cervical cancer as a major public health issue is feasible, the genotype replacement by HPV types not included in the available vaccines is an ongoing subject of research and there is no clear evidence suggesting toward this direction $(82,83)$, However, according to a transmission model by Man et al, it is still early to make clear inferences about the potential of an HPV genotype replacement, as this will depend on the ecological competition between HPV types in the community, "cross-protection" of vaccine-covered genotypes and natural immunity of the host (84).

\section{Human Polyomavirus}

Two distinct Polyomaviruses, namely JC and BK polyomavirus (JCPyV and BKPyV respectively) were the first to be recognized in humans by two independent groups in the early 1970s (85, $86)$. Since then, about 100 viral species have been recognized in insects, arthropods, fish, and mammals, 12 of which are found in humans $(87,88)$. Regarding the evolutionary history of Polyomaviruses, phylogenetic models suggest that it resides back to the last common ancestor of arthropods and vertebrates as it is estimated that at least one polyomavirus was found in this common ancestor (87). The evolutionary pattern of these relatively slowly evolving small DNA viruses resembles the one found in herpesviruses and some retroviruses, where many viral clades occur within the same host species (87).

One of the most important polyomaviruses with an oncogenic potential is the recently discovered Merkel-Cell Polyoma Virus (MCPyV), which is found in about $80 \%$ of Merkel Cell Carcinomas (MCC) (89) and MCPyV induces its carcinogenic potential mainly through its large T antigen (LT)- full-length LT and truncated LT antigen mutation (tLT) - which is a hallmark of MCC tissue, its small T antigen (sT) and the integration of the viral DNA into the host's genome (Figure 2) (89, 90). The molecular mechanisms of the tumorigenesis mediated by $\mathrm{MCPyV}$ infection include the involvement of both full-length LT and tLT antigens in the epithelial cell immortalization and transformation as indicated in rat epithelial cells, the indirect binding of p53 by full-length LT antigen and the suppression of retinoblastoma onco-suppressive proteins $(\mathrm{Rb})$ by tLT antigen (Figure 2) (91). Immunocompromised individuals are at increased risk of MCC compared to immunocompetent ones, and transcriptomic studies have revealed the pivotal interference of the LT and sT viral antigens with the host's defense mechanisms for the virus to escape the host's innate immunity (92, 93). In particular, LT and sT antigens downregulate the expression of Major Histocompatibility Complex Class I (MHCI) and Toll-like Receptor-9 (TLR-9), though in a reversible manner (Figure 2) (92, 93). This downregulation could be reversed after interferon treatment of the infected cells in the case of MHC-I and after silencing LT and sT antigens in the case 


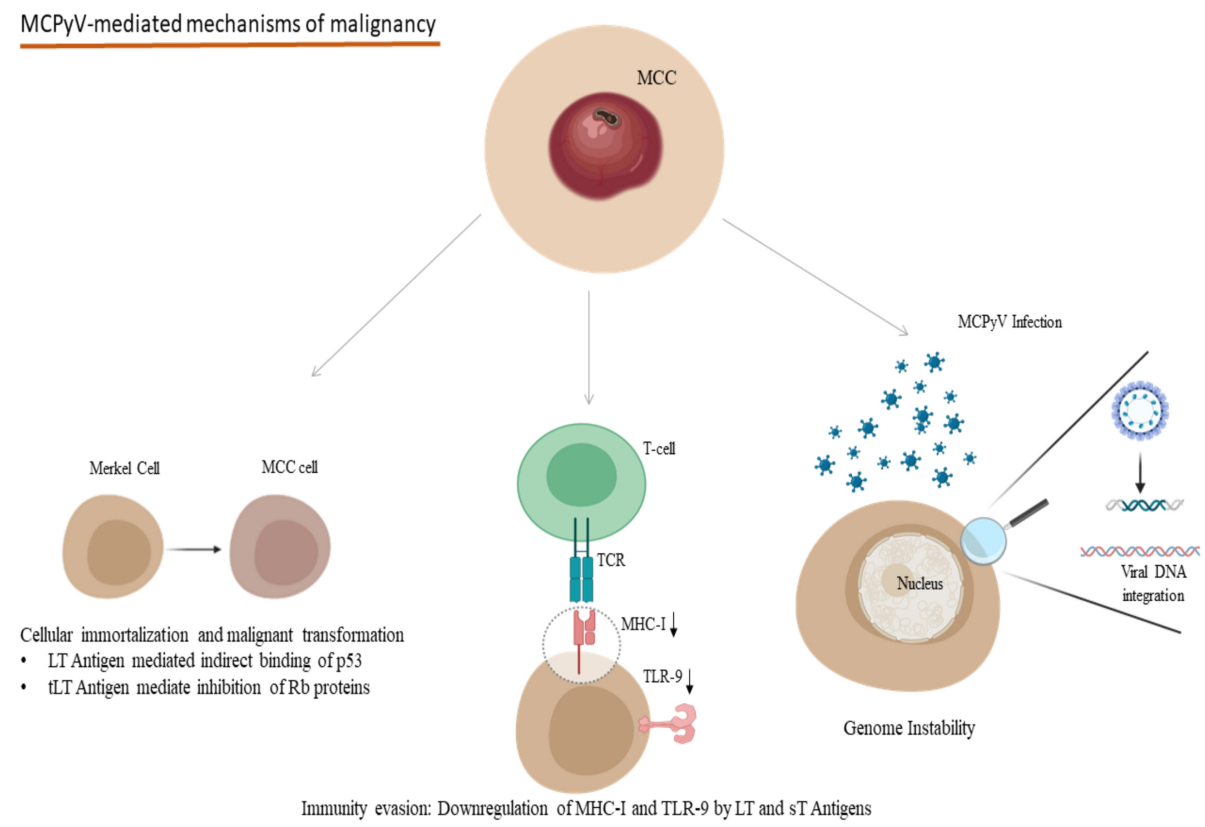

FIGURE 2 | Oncogenic mechanisms in the development of MCPyV-related MCC: Indirect binding of p53 and inhibition of Rb proteins due to LT and tLT antigens of MCPYV lead to cellular immortalization and malignant transformation. LT and ST antigens contribute to the evasion of the immune system mechanisms by downregulating MHC-I and TLR-9. Viral DNA integration to the host genome participates in genome instability. (MCPyV, Merkel Cell Polyomavirus; MCC, Merkel Cell Carcinoma; LT, Large T; tLT, truncated Large T; sT, small T, MHC-I, Major Histocompatibility Complex Class I; TLR-9, Toll-like receptor 9; TCR, T-cell receptor). Created in BioRender.com.

of TLR-9 $(92,93)$. Aside from the infection of dermal cells and Merkel cells, MCPyV DNA and a mutated form encoding for a novel truncated form of LT antigen has been recognized in chronic lymphocytic leukemia cells and this study indicates a tropism of MCPyV toward B-lymphocytes and oncogenic potential in these cells too (94). These findings suggest that a proportion of these leukemias could be attributed to the oncogenic effect of MCPyV (94). Along with the implication of $\mathrm{MCPyV}$ in the development of cancer, recent evidence suggests a potential role of other polyomaviruses in the process of carcinogenesis. Examples of these include the recognition of JCPyV DNA in the specimens of primary central nervous system malignancies as well as Human Polyoma Virus-7 (HPyV-7) DNA integrations and the expression of their respective LT antigens in thymomas $(95,96)$.

\section{Human Immunodeficiency Virus}

Deep evolutionary patterns are seen in HIV, whose epidemic resulted from cross-species transmission of Simian Immunodeficiency Viruses (SIV), which have been infecting primates for at least 32,000 years (97). The Virion infectivity factor (Vif), an accessory protein protecting retroviruses from the immune system, is functionally maintained in HIV-1,2 and SIV (98). The Vif of these viruses have distinct recognition sites, but their functionality remains similar, underlying the importance of the development of mechanisms for the effective evasion to the host's immune system (98).
The quantification of the viral reservoir and the identification of HIV integration sites in cells of HIV infected individuals could assist a deeper understanding of the increased cancer incidence of HIV-1 patients even in the era of highly active antiretroviral therapy (HAART) with which patients achieve undetectable viral loads while simultaneously contributing to the solution of the HIV persistence problem (99-101). A study conducted on a pair of monozygotic twins indicated that HIV may also cause hypermethylation, a fact which could explain the downregulation in p16 expression that can be attributed to the HIV infection (102). Ocular surface squamous neoplasia, a neoplasm related to HPV and is more common in HIVinfected individuals, demonstrates a lack of p16 expression in the majority of HIV-infected patients (103). However, the presence of p16 expression in ocular surface squamous neoplasia in HIV-infected patients predisposed to a worse prognosis (103). All these data underline the delicate balances in the inter-viral interactions with the host and the intricate malignancy mechanisms in a setting, as such.

An impediment on the comprehension of the interactions between human and HIV-1 proteins and thus immune responses to the virus is the presence of Intrinsically Disordered Proteins (IDPs) (104), proteins with disrupted 3D structures that occur at a higher rate in RNA viruses than in eukaryotes and are associated with immune dysregulation and subsequent immune system escaping of the infected cells enabling long term latency (105). 


\section{Human T-Cell Lymphotropic Virus Type-1}

The origin of Human T-cell lymphotropic virus type 1 (HTLV-1) is believed to be the interspecies infection of Simian Tlymphotropic Viruses (STLVs) from monkeys to humans in Africa that occurred around 30.000 years ago (106). Interestingly, despite structural differences, all Tax proteins among HTLV-1, $-2,-3$, and -4 preserve the $\mathrm{CBP} / \mathrm{p} 300$ binding region (107). Tax appears to be a key player in the development of malignancy mediated by HTLV-1 as it is implicated in the occurrence of almost all of the hallmarks of cancer, including cell cycle dysregulation, cell immortalization and proliferation, as well as inflammation mediated by cytokines and their receptors, but mainly by trans-activating oncogene cellular promoters (108, 109). Moreover, functionally, Tax-1 has been implicated in adverse effects on the host, such as the induction of genomic instability by inhibiting genomic repair mechanisms and thus leading to Adult T-cell Leukaemia/Lymphoma (ATLL) (107). The wide range of pathogenicity among HTLV viruses examined through comparative structural and functional analysis could specify key features, such as genes and consequently interactions related to oncogenicity (107). HTS has shed light on the effects of HTLV-1 proviral integrations on chromatin loops, causing neighboring host genome loci to approach, and thus the host transcriptional paths can be disrupted, an important mechanism of tumorigenesis (110). At a transcriptional level, HTLV-1 Tax protein affects apoptosis regulation through transcription factor $\mathrm{NF}-\kappa \mathrm{B}$ dysregulation that leads to inactivation of p53 (111).

Hypermethylation has also been involved in HTLV-1-related malignancies. In this case, hypermethylation happens as a result of mutations in genes that serve as epigenetic modulators, namely in the Ten-Eleven Translocation (TET) methylcytosine dioxygenase genes as well as in the Mixed Lineage Leukaemia (MLL) gene family (specifically in families TET2 and MLL3) (112). Regarding the TET2 family, the downregulation of its expression has been linked to the aggressiveness of malignancy (113). Finally, the study of HTLV-1 related tumorigenesis with regards to IDPs has offered information on the proteomic changes that HTLV-1 inflicts and participates in cellular malignant divergence (105).

\section{ANTI-VIRAL PROTECTIVE MECHANISMS, CHARACTERIZATION OF VIRAL INTERACTIONS IN THE HUMAN FLORA AND MICRORNAS IN CARCINOGENESIS}

Aside from the contribution of HTS in the elucidation of details of the tumorigenesis mediated by the seven recognized oncogenic viruses, it is important as well to mention the role of the development of HTS in the comprehension of human-viral interaction at the level of anti-viral intrinsic mechanisms, the participation of the virome in the structure and ecology of the human flora and the interference of viruses in the transcription regulation of the host.

\section{Zinc-Finger Proteins and Retroviral Defense}

An important regulator of the transcription of retroviruses (both endogenous and exogenous), in the human genome, are Krüppel-associated box domain-containing zinc-finger proteins (KRAB-KZFPs), that despite their unclearly defined function, appear to be a key player in the regulation of retroviral transcription at an epigenetic level, as evolutionary "young" members of this family appear to have a significant inhibitory function against retroviruses (114). The host's immune system interacts with viral elements and co-evolves with the virus to defend itself both in the short- and long-term, with Zinc-finger Antiviral Protein (ZAP) being an example of those positively selected mechanisms the discovery of which has been enabled by HTS analyses. Recently, KHNYN, a novel human protein has been recognized as an important co-factor to synergize with ZAPs in the inhibition of retroviral GC-rich RNA replication in human cells for HIV-1 (115).

However, under evolutionary pressures RNA viruses have evolved low GC dinucleotide RNA sequences in their genomes, imitating their hosts, to escape ZAP sensing which identifies elevated GC dinucleotide sequences as "foreign genome" and degrades it (116). Moreover, evidence suggests that Zinc-finger $\mathrm{CCCH}$-type containing 11A (ZC3H11A) protein, which plays a crucial role in the human cell survival during stress by maintaining proper RNA nuclear export, is hijacked by nuclear replicating viruses, as they exploit this mechanism for their own exporting and thus their survival (117).

\section{Microbiota, Virome Balance and Tumor-Viruses}

The importance of the balance during host-viral interactions, even in the commensal or symbiotic state is underscored by the recognition of the virome, along with the microbiota in human skin and mucosa. Human microbiome studies have been focused on bacteria but lately, the virome is identified as a key component for the preservation of host genome integrity. Hannigan et al. showed that bacteriophage communities of Colorectal Cancer (CRC) patients generally affect the gut microbiome and suggested that infectious phages provide nutrition, a friendly environment, and space for opportunistic pathogens to grow (118). The correlation of CRC with a distinct virome signature has also been found by other study groups, that concluded that virome could serve as a diagnostic and prognostic marker for CRC, using a taxonomic approach (119).

Intriguingly, metagenomics approaches have contributed to the recognition of hundreds of different novel HPV genomes, for the first time, in patients with deficiency of DOCK-8, an essential protein in T-cell migration through collagen-rich tissues (70), while a Lactobacillus-rich vaginal microbiota profile has been linked to protection against HPV infections, and thus reduced oncogenic burden (120).

Viruses in the commensal state in the skin have also been linked to beneficial effects in the protection against cancer, through the regulation of the host's immune system. More specifically, against the previous hypothesis that immunosuppression leads 
to increased risk of skin cancer through HPV infections, recently a novel mechanism has been proposed for this increased skin cancer incidence, as CD8(+) $\mathrm{T}$ cellular immunity against commensal HPVs in the skin microbiota suppresses the development of skin cancer in healthy hosts (121). Thus, lack of integrity of $\mathrm{T}$ cellular immunity leads to reduced control of malignant cells, and the researchers demonstrated the importance of intact $\mathrm{T}$ cell responses in the defense against chemical and ultraviolet-induced carcinogenesis in mice (121).

\section{Viral and Human microRNA Regulation in Human Malignancy Development}

Deep sequencing approaches have been able to link the expression of specific miRNAs to oncogenicity providing a potential diagnostic tool and therapeutic targets (122), an approach rather promising in the case of viral and host miRNAs interaction that is implicated in virus-related oncogenicity as well. In particular, miRNAs are non-coding RNAs that contribute and take part in the regulation of both host and viral gene expression at a post-transcriptional level. Such miRNAs originating by multiple oncogenic viruses have been correlated to procedures crucial in the development of malignancy, such as inhibition of apoptosis and cell survival, cell proliferation, immune system escape, and cell migration (123), while on the other hand cellular miRNAs appear to interact with oncoviruses (123).

The participation of viral miRNAs and their interactions with those that regulate the host's defense mechanisms has been extensively studied for EBV, the first virus for which miRNA production has been described. Forty-eight miRNAs are encoded by EBV sequences, 40 of which correspond to the BamHI-A region rightward transcript (BART) and the rest to the BamHI fragment $\mathrm{H}$ rightward open reading frame 1 (BHRF1) $(124,125)$. Interestingly with the use of HTS technology, differential expression profiles have been described for different EBVrelated malignancies, namely miR-BART11-3p, miR-BART-175p, miR-BART19-3p, and miR-BART19-5p increased transcription in B-cell tumors, and miR-BART8-3p, miRBART-7-3p, miR-BART22, and miR-BART10-3p epithelial EBV-related tumors (126). B-cell malignant transformation in the development of Burkitt lymphoma is at least partially mediated by miR-BART1 and mir-BART16, while the same miRNAs participate in the maintenance of tumor cells, even in the absence of EBV-infection in those, through targeting Caspase 3 (127). Burkitt lymphoma development is also facilitated through the miR-BART6-3-p-mediated downregulation of PTEN, affecting cell proliferation and immortalization and of WT1 and Interleukin-6, affecting the host's immune responses (128). NPC tumorigenesis and treatment resistance have been linked to miR-BHRF-1 and miR-BART5-3p, by targeting tumorsuppressor protein p53 $(129,130)$. EBV modifies the profile of miRNA expression, namely miR-31, an miRNA, participating in the cell's antitumor defense which is downregulated in EBVassociated NPC (131). TRIM8, a key player in Tumor Necrosis Factor $\alpha$ and NF- $\mathrm{\kappa B}$ signaling, which is implicated in Burkitt
Lymphoma and gastric cancer, is targeted by miR-BART16 (132). Furthermore, the interplay between the expression of viral circRNAs and oncosuppressor host miRNAs has been demonstrated by the negative correlation of the expression of the EBV-encoded circRPMS1 and tumor suppressor miRNAs, namely miR-203, miR-31, and miR-451, with the knockdown of circRPMS1, leading to reduction of NPC cell proliferation, induction of apoptosis and inhibition cell invasion, cornerstones in the pathogenesis of malignancy (133) (Figure 1). Generally, conservation of miRNA sequences among the gammaherpesvirus group is rare (134). Despite the evidence that suggest that many gammaherpesvirusese share common miRNAs, conservation of miRNA has been demonstrated only in two pairs of gammaherpesvirusese. EBV and rhesus lymphocryptovirus (rLCV) share conserved miRNAs, while rhesus rhadinovirus (RRV) and Japanese macaque herpesvirus (JMHV) share 9 premiRNAs (134). The mechanism underlying the evolution of miRNAs of herpesviruses remains elusive, although at least partially it might be explained through the evolution of host target genes. This could be explained through red queen dynamics which means that host and virus remain in balance through deep time evolution.

Regarding KSHV/HHV-8 tumorigenesis, viral miRNAs and aberrant transcription of host's miRNAs have been implicated. In a cell line with latent $\mathrm{KSHV} / \mathrm{HHV}-8$ infection, KSHV-miRK12-4-3p and KSHV-miR-K8-3p transcription demonstrated no significant difference from PEL cells, but KSHV-miR-K12-6-3p was upregulated, and KSHV-miR-K12-10a-3p downregulated in PEL cells compared to latent infection, a fact that underlines the dynamic viral miRNA expression between different stages in tumorigenesis (135). KSHV/HHV-8 infection, also, leads to the deregulation of important regulatory miRNAs of the host, including the upregulation of miR-708-5p, which induces reduced expression of Caspase- 2 and leukemia inhibitory factor, and increased expression of the p53-inhibitor MDM2, through the downregulation of cellular miR-409-5p (135). Common transcriptomic signatures have been recognized between the KSHV/HHV-8 infection and hypoxia, which led to increased transcription of cellular miR-210, a HypoxiaInducible Factor target that induces neoangiogenesis and inhibits apoptosis (136). Surprisingly, KSHV-miR-K6-5p is an "agonist" of the tumor-suppressive miR-15/16 family, leading to cell-cycle inhibition (137). This effect has been postulated to offer an evolutionary advantage to the virus by prolonging its host's survival. The participation of miRNAs in the development of virally induced-HCC has been recognized for $\mathrm{HBV}$ and $\mathrm{HCV}$ infection. Deep sequencing approaches have revealed the role of HBV-miR-3 in the establishment of HBV infection persistence and latency of the virus in liver cells (138), while this miRNA is recognized as a PTEN inhibitor, which leads to increased cell proliferation (139). Furthermore, cellular miR-522 and miR-523 are significantly upregulated in $\mathrm{HBV}$-positive $\mathrm{HCC}$ tissue compared to $\mathrm{HBV}$-negative $\mathrm{HCC}$ and their increased levels were correlated to poor outcomes (140). In HCV-induced HCC, in vitro studies revealed that despite the modest changes in the levels of cellular miRNAs, the deregulation of miR-1260a, 
miR-21*, and miR-27a*, as well as miR-483 and miR-1303 interfered with cellular lipid metabolism, while miR-122 is involved in viral persistence, by interfering with interferonrelated pathways (141). Moreover, HCV evades the host's immune system and established latency, the first step in virally-induced tumorigenesis through the upregulation of cellular miR-21 (142). Thus, type I Interferon production is hampered and the TLR signaling pathway is inhibited, leading to ongoing HCV replication (142).

Wide discrepancies have been described on the miRNA signatures of HPV-related oral and oropharyngeal head and neck cancer. Recent, RNA-seq findings pinpoint the role of HPV infection and cellular miR-9 (143). HPV-E6 protein is one candidate up-regulator for miR-9 leading to cellular proliferation and migration in the setting of oropharyngeal and cervical cancers (143). Small RNA-sequencing analysis (sRNAseq) offers interesting perspectives in the diagnosis of HPVinduced lesions, as sRNA-seq in HPV-positive samples with cervical precancer was capable to reveal a distinct miRNA profile of 9 miRNAs, namely let-7b, miR-9, miR-15b, miR-20a, miR-31, miR-93, miR-183, miR-184, miR-222 (144). Our understanding of the HPV encoded miRNAs is currently limited. HPV encoded miRNAs have been recognized and appear to take part in HPVmediated carcinogenesis (145). For example, HPV16-miR-H1-1 targets genes involved in T-cell activation, cellular adhesion and cell migration, cell growth, survival, and proliferation (145). Computational analyses revealed 19 pre-miRNAs (HPV-premiRNAs), varying between HPV types (146). The role of miRNAs in the induction of MCPyV-induced malignancy is controversial, as their low-level expression was considered unlikely to participate in viral carcinogenesis (147). However, recently exosome-shuttle miR-375 was found in Merkel cell carcinoma tissue and can be considered as a mediator of malignancy by downregulating p53 (148).

Many studies have demonstrated that cellular miRNA profile is altered after HIV infection and multiple miRNAs target viral sequences functioning as a host defense mechanism against infection (123). Significant upregulations of DNMT3a and DNMT3b, correlated to decreased transcription of miR29 and miR148-152, have been described in aggressive B-cell lymphomas in HIV-positive individuals, indicating aberrant methylation patterns due to miRNA transcription in response to HIV infection (149). Additionally, the other important carcinogenic retrovirus, HTLV-1, has been correlated to miRNA dysregulation of the host both during its asymptomatic carriage and at the presence of ATLL. For example, significant upregulation of miR-451a and downregulation of miR-142-3p in ATLL were reported compared to healthy control samples, which were correlated to THBS4 upregulation and increased cell migration, and invasion (150). A highly conserved miRNA with tumor-suppressor properties, that is involved in the $\mathrm{p} 53$ pathway and is decreased in many tumors, miR-34a (151), was found elevated in Peripheral Blood Mononuclear Cells (PBMCs), early after their infection with HTLV-1 as well as in the PBMCs of patients with ATLL, indicating the consistent miR-34a upregulation during the course of HTLV-1 latency and HTLV- 1-related malignant transformation (152). Surprisingly, miR-34a upregulation was correlated to increased survival of the HTLV-1infected T-cells, as its knock-down led to death of the HTLV-1infected cells (152). NF- $\kappa \beta$ pathway activation appears to be important in the maintenance of the expression of miR-34a, and HTLV-1 Tax was proposed by the researchers as a potential mediator of the role of miR-34a in HTLV-1 tumorigenesis, due to its potent role as an NF- $\kappa \beta$ pathway activator (152). However, further research is warranted on the pathways that are associated with the miR-34a role in the development of HTLV-1 malignancy, as the expression of HTLV-1 Tax is significantly reduced and almost disappears in ATLL cells (152). These findings underline the role of other not yet recognized molecular pathways related to the role of this miRNA (152). Recently, an sRNA-seq analysis revealed a distinct profile of miRNA expression in the PBMCs of HTLV-1 asymptomatic carriers compared to controls, a fact that may underline their role in latency and malignant hallmark development (153).

\section{THE ENEMY WITHIN: HTS PROVIDES DEEP INSIGHT INTO HUMAN ENDOGENOUS RETROVIRUSES}

HERVs are retroviral elements in the human genome, that have integrated into our ancient ancestors' germ-line cells and were preserved through Mendelian inheritance (154). The coevolution of Endogenous Retroviruses (ERVs) with their jawed vertebrate hosts has taken place for over $450 \mathrm{My}$ (155). The majority of ERV integrations have become replication- and retrotransposition-defective and remain under strict transcriptomic control (156). These ancient pathogens have lost their ability to replicate and re-infect by the accumulation of multiple mutations, including deleterious insertions and deletions, often causing frameshifts as well as homologous recombination events, leading to the creation of solitary Long Terminal Repeats (LTRs) and the total disappearance of the viral gene coding sequences. due to the evolutionary pressure, they imposed on the physiologic functions of their mammalian hosts. Along with their participation in the retroviral integration, the LTRs flanking endogenous retroviruses function also as regulatory elements, with promoter and enhancer function (157). Given the versatile functions of HERV transcripts and proteins in the hosts' fitness and diseases, HERVs cannot be considered as "junk DNA" as previously perceived, but appear to have multiple implications in hosts' evolution, health and disease. Their co-option cannot be attributed with confidence to a specific reason but there is a list of candidates linked to evolutionary advantages for the host that could be responsible for their maintenance in the human genome.

In this part of our manuscript, we will review evidence showing that HERVs are linked to a variety of tumorigenic mechanisms such as chromatin structure modification and imprinting, transcriptional modulation, and post-transcriptional regulatory networks. 


\section{HERVs-Exogenous Viruses' Interplay Along With the Maternal-Fetal Paradox: Insights to Cancer Immune Escape?}

One of the most important characteristics of HERVs is their involvement in placentation with a similar protein to mammals' retroviral-envelope (Env) protein in an independently evolved lizard with placentotrophic reproduction (158). Env protein apart from being co-opted to serve syncytiotrophoblast formation in placentation is also inversely correlated to the ability of ERVs to spread within host genomes and thus offers protection to the developing organisms (159). What is more, env transcripts are found mainly in the fetal part of the placenta, while the maternal part remains relatively poor in retroviral expression (160). This observation underlines the benefits of this retroviral presence in the side of the developing embryo, rather than the maternal side.

In particular, two HERV-derived Env-proteins, Syncytin-1, the Env protein of HERV-W, and Syncytin-2, which is encoded by HERV-FRD, have been implicated in the process of proper placentation and cell-cell fusion (161). Both Syncytin-1 and Syncytin-2 contribute to syncytialization by their expression during placentation, leading to the fusion of the villous trophoblast to the syncytiotrophoblast (162). Syncytin-1 is expressed in the extravillous trophoblast and the villous trophoblast, while Syncytin-2 is expressed solely in the villous trophoblast (161). Syncytin-1 and Syncytin-2 function after their ligation to their cognate receptors $\mathrm{Na}$-dependent neutral amino acid transporter 2 (ASCT2) and Major Facilitator Superfamily Domain Containing 2 (MFSD2) $(161,162)$. The importance of these HERV-derived proteins in the normal placental formation is pointed out by the observed deregulation of Syncytin-1 expression in the setting of placental syndromes, such as pre-eclampsia, probably offering smaller advantages to those fetuses (163) and of Syncytin-2 in chromosomally abnormal trophoblastic tissues, which leads to insufficient syncytialization and subsequent spontaneous pregnancy loss (164). Simultaneously, the overexpression of methyltransferases, recognized in these tissues, implicates an aberrant epigenetic regulation of HERVs (163).

Intriguingly, an Env protein encoded by HERV-Fb1 (ERVH48-1), Suppressyn (SUPYN) has been recognized in vivo placental samples and in vitro in cell lines as an inhibitor of cellcell fusion in mammals and its sequence appears to be highly conserved through simian evolution (165). SUPYN is a Syncytin1-specific inhibitor, with which it shares its cognate receptor (ASCT2) (165). Furthermore, these two proteins share similar cell-type expression patterns and are both expressed in villous and extravillous trophoblast (165). The ligation of SUPYN to ASCT2 has been proposed to serve beneficial functions for the host. Most importantly, SUPYN is hypothesized as a mediator in syncytialization regulation to avoid aberrant placentation (166). Oxygen levels at the maternal-fetal interface have been implicated in the development of pre-eclampsia and reduced SUPYN expression in a state of hyperoxia is presumed to lead to maternal exposure to placental debris, disruptions in the maternal spiral artery remodeling and could lead to the hallmarks of preeclampsia (166).
Endogenous viral elements interfere with immunity and antiviral defense, and their preservation is similar to that of another set of pregnancy-associated genes, the Killer-cell Immunoglobulin-like Receptor (KIR) family whose expression seems to be pathogen-driven (167). There is an increased interest in the association between HERVs and the "paradox of pregnancy": pregnancy is compared to semi-allograft, but the fetus manages to avoid maternal immunity $(168,169)$. The disturbance of this balance could lead to a pro-inflammatory cytokine storm and distressing events resulting in miscarriage (170). This "series of unfortunate events" could be attributed to viral infections, a fact that pinpoints that HERVs are under continuous selective pressure. HERV-K expression is suggested to protect pre-implantation embryos from exogenous viral infections which could lead to their preservation due to natural selection (171).

All these findings underscore the importance of HERVderived Env protein in the successful cellular fusion during placentation, placental integrity, and fetal-maternal health. Thus, it is reasonable to assume that the tolerance of the immune responses to cancer could be at least partially attributed to the upregulation of HERVs expression that is widely observed in a variety of tumors (172).

\section{Oncoviruses and HERVs Interactions}

Oncoviruses seem to regulate HERV expression through different pathways like host immunosuppression, production of viral transcriptional factors, chromatin dysregulation, and epigenetic modifications (173). Especially for HERV-K HML2 (HK2) a wide range of interactions has been described with oncoviruses.

HIV-1 infection increases expression of HK2 through the Tat protein, as shown in vitro when treatment of primary lymphocytes and Jurkat T-cell with recombinant HIV-1 Tat protein led to an upregulation in rec and $n p 9$, and gag expression respectively by promoter activation facilitated by NF- $\kappa B$ and NF-AT transcription factors (Figure 3) $(174,175)$ which might contribute to the pathophysiology of cancer development in HIV-1 infection. Moreover, there are indications that HIV Tat protein elaborates a cell-type-specific regulation of syncytin-1 expression which is translated as inhibition in monocytes and stimulation in differentiated macrophages (Figure 3) (176). On the other hand, reduced HIV replication was linked to the expression of HERV-K108's (a type-2 HERV-K HML-2) Env protein (177). HERV-K18 Env protein demonstrated an ability to be incorporated in HIV but not SIV particles and this interaction between this endogenous and an exogenous retrovirus could be an important mediator in the immune escape of HIV-1 and its carcinogenesis (178). HIV-1 infection, also, at a transcriptional level, leads to the production of a fully glycosylated HK2 Env protein on the surface mononuclear cells of HIV-infected individuals (179). Furthermore, this HK2 Env protein is immunogenic, leading to the production of antibodies against it, the titters of which are particularly elevated in HIV-infected individuals that do not receive treatment (179). 


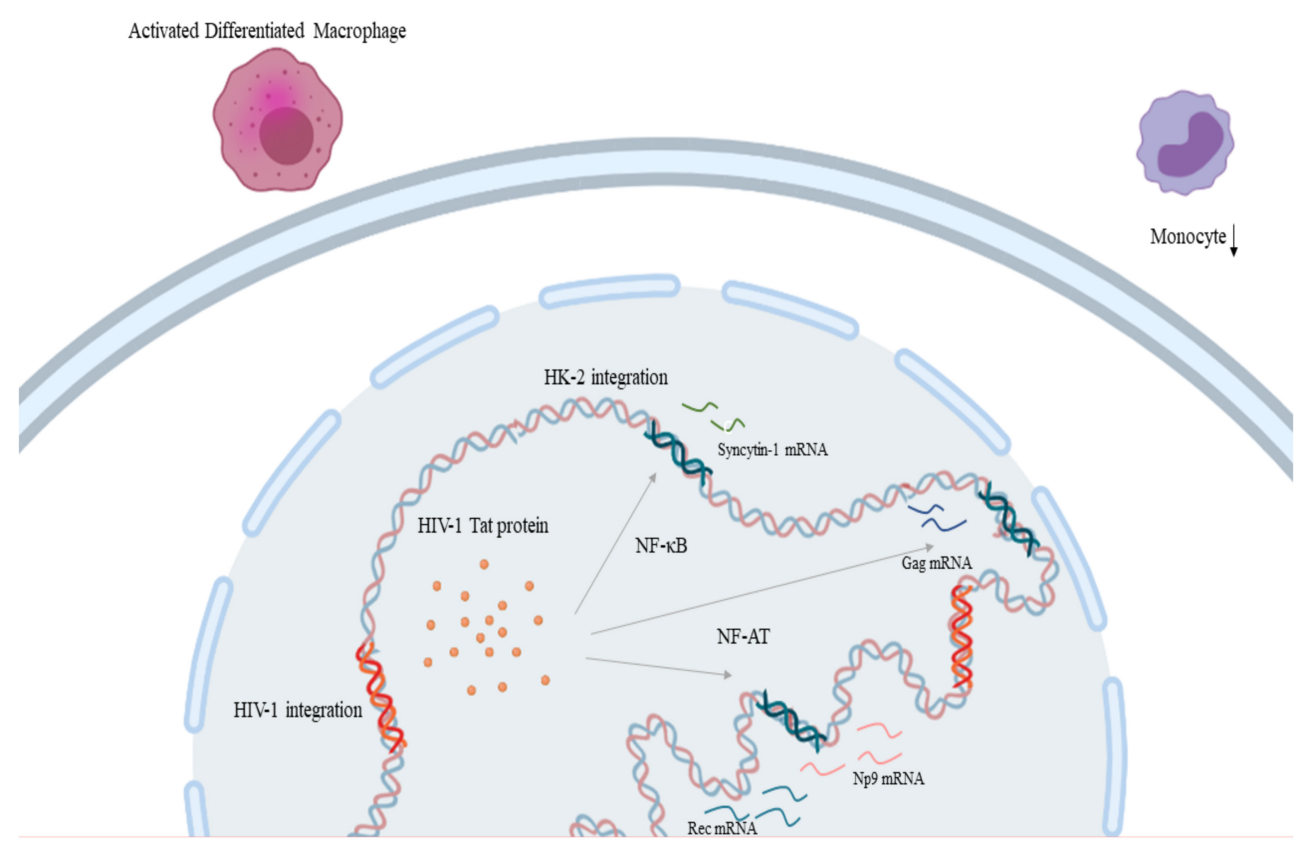

FIGURE 3 | HIV-1 and HERV-K HML-2 interaction in the process of carcinogenesis: HIV-1 Tat protein leads to the upregulation of rec and np9, and gag expression through transcription factors NF-kB and NF-AT respectively. Also, HIV-1 Tat protein leads to the inhibition of monocytes and stimulation in differentiated macrophages through syncytin-1 expression. (HIV-1, Human Immunodeficiency Virus 1; HERV-K HML-2, Human Endogenous Retrovirus HML-2). Created in BioRender.com.

HK2 is transactivated by KSHV/HHV-8 and has been suggested to contribute to the pathophysiology of immunosuppression through Np9, thus contributing to the development of Kaposi's sarcoma (180). Transactivation of HERV-K18 was noticed in cases associated with EBV (181). EBV has also been shown to upregulate syncytin-1 expression in astrocytes, B-cells, and monocytes (182). EBV also activates various LTRs through hypomethylation without however this being sufficient to cause carcinogenesis. Subsequently, it was assumed that DNA hypomethylation and transcription factors collaborate towards carcinogenesis (183). Recently, HBV $\mathrm{X}$ protein has been associated with the upregulation of syncytin-1 and the production of both spliced and unspliced transcripts (184). Finally, HTLV-1 Tax is associated with the upregulation of the LTRs and the promoter activity of HERV-H and HERV-W8 sequences, as the use of an HTLV-1 Tax transactivator on Jurkat cells demonstrated similar effect on the T-cell activation with the effect of a potent combination of T-cell stimulating agents: bpV[pic], a cAMP pathway activator, with Forskolin, an inhibitor of Tyrosine phosphatases, and PMA, a protein kinase $\mathrm{C}$ activator, respectively (185). Data concerning the remaining oncoviruses are insufficient and remain controversial.

\section{Evolutionary Pressure on HERVs Through Cancer}

The total number of HERVs in the human genome over the past 10 million years has been declining while the acquisition of new and expansion of old families is observed in other species (186). Body size was connected with declining ERVs integrations probably as a potential defense mechanism against tumorigenesis and this is suggested to be relevant to Peto's paradox, however, this characteristic on its own could not justify the differences mentioned above (187). However, the "golden ratio" of HERVs' activity for both viral and human survival remains to be established, since some of their "evolutionary virtues" could also be linked to unfortunate events like cancers (172). Of note, viral activity is subject to a lesser degree of transcription control in the elderly in comparison to younger individuals, an important point when considering virus-host interactions under the prism of evolution, with evidence suggesting HERV-K transcription, being found higher in older healthy individuals compared to younger healthy ones (188), an observation that could be correlated to the fact that tumorigenesis is more prevailing in older individuals.

\section{HERVs, Pluripotency and Cancer Stem Cells}

Adult cells can be reprogrammed via multiple experimental procedures altering their gene expression patterns $(189,190)$. Despite the differences regarding the growth factors used to induce pluripotency, these variable procedures share common features and obey the same disciplines when it comes to HERV expression. HERV-H appears to be of great importance, in early events of reprogramming, with the expression of LTR7 in induced Pluripotent Stem Cells (PSC) higher in comparison to Embryonic Stem Cells (ESC) (191). On the other hand, a loss of 
function study showed that HERV-FRD is a suppressing factor for induced PSC reprogramming (192).

HERVs' role in the process of carcinogenesis is indicated by their part in cell reprogramming of Cancer Stem Cells (CSC) which are thought to be responsible for tumor initiation, progression, and maintenance, metastatic dissemination, and recurrence (193). HERVs entanglement has been implied mainly due to reports of upregulation after treatment. HERVWE1, HERV-FRD1, HERV-31, and HERV-V1 have appeared elevated in treatment-naïve colon carcinoma cells after cytostatic interventions (194). Moreover, HERV-H elements were shown to be able to activate Topologically Associating Domains' (TAD) boundaries in PSCs (195), inducing gene transcription. TAD boundaries are considered able to lead to carcinogenesis when disrupted or rearranged (196). In combination, these indications provide a theoretical framework adept at implying a link among HERVs, pluripotency, and carcinogenesis (197).

Finally, inflammation has variable effects on stem cells. That given, HERVs have been shown to activate immune and inflammatory responses when their RNA is recognized as a pathogen-associated molecular pattern (198). Accordingly, in the case of CSC, HERVs could induce more aggressive types of cancer through inflammation such as in endometrial carcinoma (199) and melanoma (200).

\section{HERVs and Human Cancer: Link, Therapeutic and Prognostic Perspectives}

Unlike cancer development in other mammals, most strikingly in mice, where infectious endogenous retroviruses Mouse Mammary Tumor Virus (MMTV) and Mouse Leukemia Virus (MLV) are the causative agents of the respective malignancies, endogenous retroviral transcription and activity have not been directly and conclusively linked to human malignancy (201). However, HERVs are characterized by multiple traits that make them strong candidates for participating in human tumorigenesis, as it is evident that human carcinogenesis is a rather multifactorial process and, to its greater extend, not yet elucidated. There are many ways that ERVs can be considered an important player in human carcinogenesis. Many HERV LTRs can serve as promoters and enhancers for transcription and affect the regulation of gene expression with this activity more pronounced around gene-loci and transcriptional dysregulation is an important characteristic in cancer development (202-204). One-third of all p53 DNA binding sites are included in HERV sequences (205). To date, evidence points to contradicting roles in cancer in humans. Many ERV families have been linked to increased tumorigenic burden and appear to affect the prognosis to the worst while on the other hand, the immune responses that are mediated through ERV expression like innate immunity upregulation with interferonogenic reactions (206), are found to have cancer-limiting effects in some neoplasias (207). In this chapter, we aim to discuss selected examples of the manifold and multi-faceted effects of HERV expression in the development and prognosis of human cancer.

Many studies have demonstrated a potential implication of ERVs in a wide spectrum of human malignancies including hematologic malignancies and solid tumors. High expression levels of the Env protein of ERV-3-1 were found in all patients with Acute myeloid leukemia (AML) included in one cohort while this effect was more specific for bone marrow and blood cells and was closely associated with a myeloid phenotype of AML in this study (208). Concerning hematologic malignancies, Myelodysplastic syndrome (MDS) is a heterogeneous category of hematological diseases that are recognized predisposition factors for the development of myeloid lineage malignancies, most commonly myeloid leukemia (209). Upregulated expression of ERV-K6, ERV-W1, and ERV-3-1 is associated with the presence of dyserythropoiesis in MDS. The upregulation of these ERVs participates in the induction of this phenotype, by stimulating TLR3 expression resulting in the expression of transcription factors including Interferon Regulatory Factors (IRFs), IRF-3, and IRF-7, as well as NF- $\kappa$ B leading to increased inflammatory burden (209). In contrast, in multiple myeloma, a hematologic malignancy, characterized by methylation pattern dysregulations (210), concomitant inhibition of two distinct methyltransferases, namely EZH2 and G9a, led to ERVs activation by interfering with their methylation-mediated silencing, which in turn stimulated type I interferonogenic reactions (211). This inflammatory response led by ERV transcription, when activated, demonstrated induction of apoptosis and subsequently antimyeloma effects (211).

Regarding solid tumors, breast cancer is one well-studied paradigm of correlation of HERVs to cancer development. HK2 Env protein co-operates with multiple environmental and hostimmune factors and exercises a tumorigenic effect on human breast epithelial cells in vitro, by inducing cellular phenotype shift to mesenchymal and increased cell migration and evasion dynamics leading to metastatic potential (212). HK2 serum mRNA and HK2 specific antibodies have been proposed in aiding early diagnosis in breast cancer as their levels in patients with ductal carcinoma in situ were significantly higher than in healthy women (213). The levels of these ERV-related biomarkers demonstrated a dose-dependent effect with regards to the progression of tumors and their increase could also predict the occurrence of metastases in breast cancer patients (213). This observed HK2 dysregulation in breast cancer patients is more evident in breast cancer in HIV-infected women, which indicates the retroviral interactions between HK2 and HIV in the upregulation of HK2 in these tumors (214). Lung adenocarcinoma in never-smoker female patients has been linked to polymorphic HK2 integration sites in homozygosity (215). This observation makes the scenario of a potential role of ERVs in human cancer plausible, as this is a rare form of the disease, lacking the usual exposures of this malignancy. Furthermore, metagenomic analyses in the virome of lung cancer tissues and blood from lung adenocarcinoma revealed the presence of multiple HERV families (216).

HERV expression has also been considered as a potential prognostic factor in the disease course and survival in many cancers and their presence affects these characteristics in multiple manners. Colorectal cancer tissues characterized by increased endogenous retroviral expression combined with a 
CD8(+) infiltration, have been linked to increased inflammatory burden and unfavorable prognosis in terms of treatment response and disease recurrence (217). HERV-W syncytin-1 expression in endometrial epithelial cancer induces cell transformation to mesenchymal, cell proliferation as well as cell migration and adhesion increasing the metastatic potential of the tumor (199). Likewise, HERV-K induction in malignant melanoma increases the melanoma cell stemness and transformation potential, invasion and migration capacity, increasing its overall malignant dynamic (200). Regarding melanoma, HK2 Rec protein is implicated in the regulation of Melanocyte Inducing Transcription Factor (MIFT) and MIFT, which in turn, causes the upregulation of HERV-K LTR and proviral expression, implying a loop between MIFT and HERV$\mathrm{K}$ transcription in the development of the disease $(218,219)$. HK2 Np9 accessory protein has been implicated in the development and characteristics of teratocarcinoma. In vitro data suggest that Np9 may have oncogenic potential, as its depletion decreased the malignant potential of the teratocarcinoma NCCIT cell line and made these cells more susceptible to bleomycin and cisplatin (220). Mechanisms of the contribution of HERVs in the development of the hallmarks of cancer are summarized in Figure 4.

On the other hand, a HERV expression-based score for epithelial ovarian cancer was built, and higher scores were associated with longer survival and better prognosis (207). In vitro, it was shown that DNA methyltransferase inhibition led to ERV-mediated interferonogenic reactions, that activated CD8(+) cytotoxic cells that induced epithelial cancer cell killing (207). Interestingly, clear cell Renal Cell Carcinoma (ccRCC) demonstrates overexpression of a retroviral antigen derived from a member of the HERV-E family (CT-RCC HERV-E or ERVE-4), compared to healthy tissues, which can be identified by antigen-specific CD8(+) $\mathrm{T}$-cells, as has been reported in a patient who experienced regression of metastatic ccRCC after allogeneic hematopoietic stem cell transplantation (221). More specifically, transcription of the entire env gene of both domains (surface and transmembrane) of CT-RCC HERV-E is detected in ccRCC cells and CD8(+) T-cells were capable to identify HERVE expressing ccRCC tumor cells that are HLA-A*0201 positive (222). However, CT-RCC HERV-E expression does not appear to take place solely in ccRCC cells, as it has been recognized to have translational capacity, also, in lymphoblastic cell lines, which may indicate the potential this HERV-E family member to be expressed in malignant cells in general (223).

Among all cancers analyzed by Smith et al. with respect to their HERV expression patterns, ccRCC demonstrated the greatest number of HERVs with potential prognostic value (223). Interestingly, a recombinant integration of HERV-E (chromosome 19, positions 29097422-29106221) that has been named as hERV 4700, which demonstrated the highest level of expression in ccRCC tissues compared to healthy tissues, demonstrated strong evidence of translation in ccRCC tissues (223). More specifically, predicted hERV 4700 epitopes in ccRCC tumours originate from gag, pol and env sequences, and infiltrating T-cells specific for the gag- and pol-derived epitopes of hERV 4700 are described in ccRCC tissues, while these hERV 4700-specific T-cells are hardly present in PBMC populations of healthy donors (223). Thus, hERV 4700-epitopes are able to elicit T-cell responses against ccRCC cells, and hERV 4700 expression can be considered a biomarker of responsiveness of ccRCC tumors to checkpoint inhibitor anticancer treatments (223).

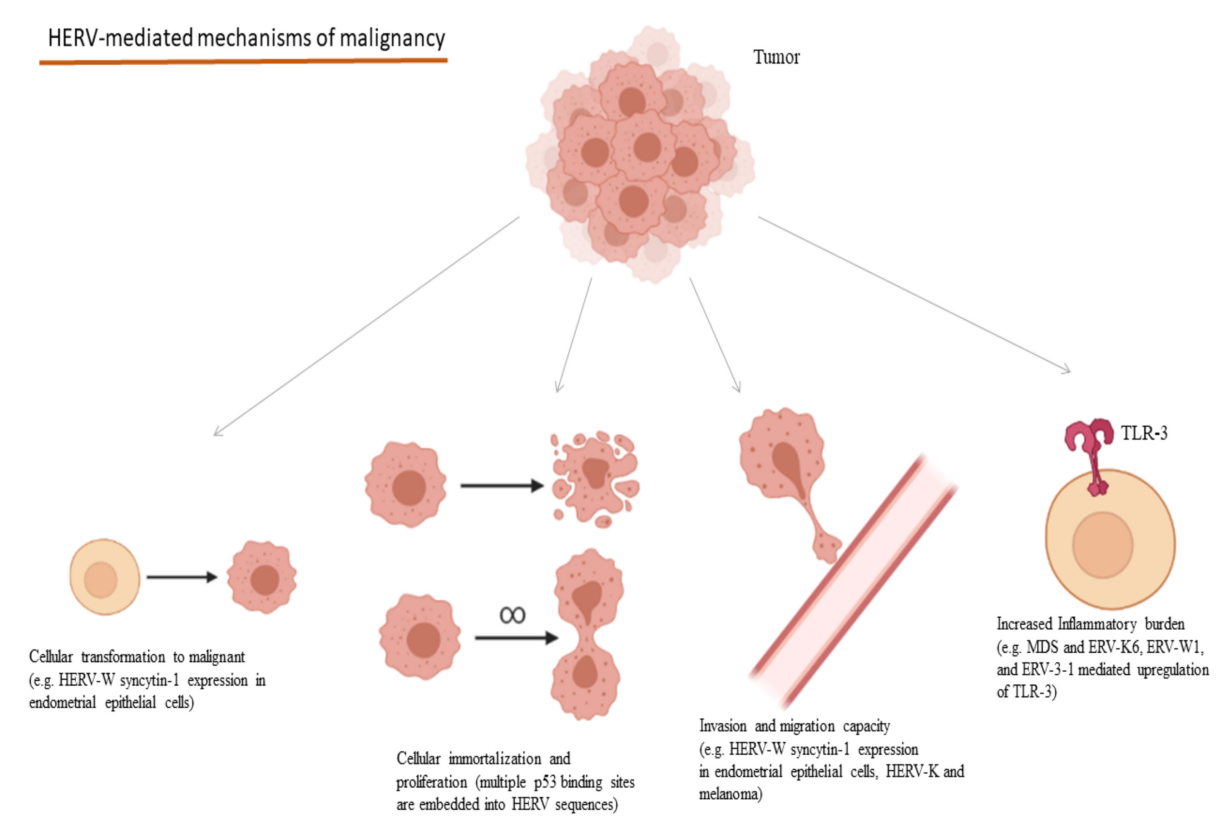

FIGURE 4 | Oncogenic mechanisms mediated through HERVs and selected examples of their implications in cancers. (HERV, Human Endogenous Retrovirus; MDS, Myelodysplastic Syndrome; TLR, Toll-like Receptor). Created in BioRender.com. 
Bearing in mind that ccRCC is a malignancy with a poor prognosis, further studies on the role of HERV-E family are required, as this HERV may provide the scientific community with promising novel cancer immunotherapy targets.

\section{CONCLUSION}

Our understanding of the role of free-living and endogenized human viruses in the development of cancer has greatly improved over the last few years. The revolution of high throughput sequencing technologies has allowed us to reveal hidden interactions, and we now see deeper and more perplexing relationships within the network of interactions of humans and a better-understood variety of viral forms. It has, thus, become clearer that the human-virus evolutionary gameplay is mainly driven by the pleiotropic effects of the viral ecology on the human host. In the case of ERVs, their intricate evolutionary history and the multiplicity of their roles in the pathogenesis of

\section{REFERENCES}

1. Cadwell K. The Virome in Host Health and Disease. Immunity (2015) 42:805-13. doi: 10.1016/j.immuni.2015.05.003

2. Oh JK, Weiderpass E. Infection and Cancer: Global Distribution and Burden of Diseases. Ann Glob Heal (2014) 80:384-92. doi: 10.1016/ j.aogh.2014.09.013

3. White MK, Pagano JS, Khalili K. Viruses and Human Cancers: A Long Road of Discovery of Molecular Paradigms. Clin Microbiol Rev (2014) 27:463-81. doi: 10.1128/CMR.00124-13

4. International Agency for Research on Cancer. Weltgesundheitsorganisation Eds. IARC Monographs on the Evaluation of Carcinogenic Risks to Humans, Volume 100 B, Biological Agents: This Publication Represents the Views and Expert Opinions of an IARC Working Group on the Evaluation of Carcinogenic Risks to Humans, Which Met in Lyon Vol. 24. Lyon: IARC (2012).

5. Bouvard V, Baan R, Straif K, Grosse Y, Secretan B, El Ghissassi F, et al. A Review of Human Carcinogens-Part B: Biological Agents. Lancet Oncol (2009) 10:321-2. doi: 10.1016/s1470-2045(09)70096-8

6. The Cancer Genome Atlas Research Network, Weinstein JN, Collisson EA, Mills GB, Shaw KRM, Ozenberger BA, et al. The Cancer Genome Atlas Pan-Cancer Analysis Project. Nat Genet (2013) 45:1113-20. doi: 10.1038/ng.2764

7. Garrido-Cardenas JA, Manzano-Agugliaro F. The Metagenomics Worldwide Research. Curr Genet (2017) 63:819-29. doi: 10.1007/s00294017-0693-8

8. Bhuvaneshwar K, Song L, Madhavan S, Gusev Y. viGEN: An Open Source Pipeline for the Detection and Quantification of Viral RNA in Human Tumors. Front Microbiol (2018) 9:1172. doi: 10.3389/fmicb.2018.01172

9. Stricker SH, Köferle A, Beck S. From Profiles to Function in Epigenomics. Nat Rev Genet (2016) 18:51-66. doi: 10.1038/nrg.2016.138

10. Cai X, Schäfer A, Lu S, Bilello JP, Desrosiers RC, Edwards R, et al. EpsteinBarr Virus microRNAs Are Evolutionarily Conserved and Differentially Expressed. PloS Pathog (2006) 2:0236-47. doi: 10.1371/journal.ppat.0020023

11. Murer A, Rühl J, Zbinden A, Capaul R, Hammerschmidt W, Chijioke O, et al. MicroRNAs of Epstein-Barr Virus Attenuate T-Cell-Mediated Immune Control In Vivo. MBio (2019) 10:e01941-18. doi: 10.1128/mBio.01941-18

12. Ungerleider NA, Jain V, Wang Y, Maness NJ, Blair RV, Alvarez X, et al. Comparative Analysis of Gammaherpesvirus Circular RNA Repertoires: Conserved and Unique Viral Circular RNAs. J Virol (2019) 93:e01952-18. doi: 10.1128/JVI.01952-18

13. Toptan T, Abere B, Nalesnik MA, Swerdlow SH, Ranganathan S, Lee N, et al. Circular DNA Tumor Viruses Make Circular RNAs. Proc Natl Acad Sci USA (2018) 115:E8737-45. doi: 10.1073/pnas.1811728115 human malignancy warrants further investigation which is promising for the provision of novel diagnostic and therapeutic perspectives. However, even though viruses remain an established cause of cancer, their molecular pathways remain to be disentangled. As we shed light on these pathways, we foresee that a better understanding of cancer will emerge as well as novel avenues for therapeutic intervention.

\section{AUTHOR CONTRIBUTIONS}

KK: Writing- Original draft preparation, Writing- Reviewing and Editing. MI: Conceptualization, Writing- Original draft preparation, Writing- Reviewing and Editing. VS: Writing- Reviewing and Editing. PL: Conceptualization, Writing- Reviewing and Editing. GM: Conceptualization, Writing- Reviewing and Editing, Supervision. All authors contributed to the article and approved the submitted version.

14. Kanda T, Yajima M, Ikuta K. Epstein-Barr Virus Strain Variation and Cancer. Cancer Sci (2019) 110:1132-9. doi: 10.1111/cas.13954

15. Xu M, Yao Y, Chen H, Zhang S, Cao SM, Zhang Z, et al. Genome Sequencing Analysis Identifies Epstein-Barr Virus Subtypes Associated With High Risk of Nasopharyngeal Carcinoma. Nat Genet (2019) 51:1131. doi: 10.1038/ s41588-019-0436-5

16. Correia S, Bridges R, Wegner F, Venturini C, Palser A, Middeldorp JM, et al. Sequence Variation of Epstein-Barr Virus: Viral Types, Geography, Codon Usage, and Diseases. J Virol (2018) 92:e01132-18. doi: 10.1128/ JVI.01132-18

17. Dheekollu J, Malecka K, Wiedmer A, Delecluse HJ, Chiang AKS, Altieri DC, et al. Carcinoma-Risk Variant of EBNA1 Deregulates Epstein-Barr Virus Episomal Latency. Oncotarget (2017) 8:7248-64. doi: 10.18632/ oncotarget.14540

18. Okabe A, Funata S, Matsusaka K, Namba H, Fukuyo M, Rahmutulla B, et al. Regulation of Tumour Related Genes by Dynamic Epigenetic Alteration at Enhancer Regions in Gastric Epithelial Cells Infected by Epstein-Barr Virus. Sci Rep (2017) 7:7924. doi: 10.1038/s41598-017-08370-7

19. Leonard S, Wei W, Anderton J, Vockerodt M, Rowe M, Murray PG, et al. Epigenetic and Transcriptional Changes Which Follow Epstein-Barr Virus Infection of Germinal Center B Cells and Their Relevance to the Pathogenesis of Hodgkin's Lymphoma. J Virol (2011) 85:9568-77. doi: 10.1128/jvi.00468-11

20. Maruo S, Zhao B, Johannsen E, Kieff E, Zou J, Takada K. Epstein-Barr Virus Nuclear Antigens 3C and 3A Maintain Lymphoblastoid Cell Growth by Repressing P16ink4a and P14arf Expression. Proc Natl Acad Sci USA (2011) 108:1919-24. doi: 10.1073/pnas.1019599108

21. Zhao P, Lu Y, Liu L, Zhong M. Aberrant Cytoplasmic Expression of Cyclin B1 Protein and Its Correlation With EBV-LMP1, P53 and P16(INK4A) in Classical Hodgkin Lymphoma in China. Pathol Oncol Res (2011) 17:369-73. doi: 10.1007/s12253-010-9335-x

22. Al-Salam S, Awwad A, Sudhadevi M, Daoud S, Nagelkerke NJD, Castella A, et al. Epstein-Barr Virus Infection Correlates With the Expression of COX-2, P16ink4a and P53 in Classic Hodgkin Lymphoma. Int J Clin Exp Pathol (2013) 6:2765-77.

23. Hui KF, Ho DN, Tsang CM, Middeldorp JM, Tsao GSW, Chiang AKS. Activation of Lytic Cycle of Epstein-Barr Virus by Suberoylanilide Hydroxamic Acid Leads to Apoptosis and Tumor Growth Suppression of Nasopharyngeal Carcinoma. Int J Cancer (2012) 131:1930-40. doi: 10.1002/ ijc. 27439

24. Yin H, Qu J, Peng Q, Gan R. Molecular Mechanisms of EBV-Driven Cell Cycle Progression and Oncogenesis. Med Microbiol Immunol (2019) 208:573-83. doi: 10.1007/s00430-018-0570-1 
25. Forrest C, Hislop AD, Rickinson AB, Zuo J. Proteome-Wide Analysis of CD8+ T Cell Responses to EBV Reveals Differences Between Primary and Persistent Infection. PloS Pathog (2018) 14:e1007110. doi: 10.1371/ journal.ppat.1007110

26. Ersing I, Nobre L, Wang LW, Soday L, Ma Y, Paulo JA, et al. A Temporal Proteomic Map of Epstein-Barr Virus Lytic Replication in B Cells. Cell Rep (2017) 19:1479-93. doi: 10.1016/j.celrep.2017.04.062

27. Sanjuán R, Domingo-Calap P. Mechanisms of Viral Mutation. Cell Mol Life Sci (2016) 73:4433-48. doi: 10.1007/S00018-016-2299-6

28. Cordiali-Fei P, Trento E, Giovanetti M, Lo Presti A, Latini A, Giuliani M, et al. Analysis of the ORFK1 Hypervariable Regions Reveal Distinct HHV-8 Clustering in Kaposi's Sarcoma and Non-Kaposi's Cases. J Exp Clin Cancer Res (2015) 34:1-12. doi: 10.1186/S13046-014-0119-0

29. Aiewsakun P, Katzourakis A. Time-Dependent Rate Phenomenon in Viruses. J Virol (2016) 90:7184. doi: 10.1128/JVI.00593-16

30. Liu Z, Fang Q, Zuo J, Minhas V, Wood C, He N, et al. Was Kaposi's Sarcoma-Associated Herpesvirus Introduced Into China via the Ancient Silk Road? An Evolutionary Perspective. Arch Virol (2017) 162:3061-8. doi: 10.1007/s00705-017-3467-1

31. Rescigno P. Non-AIDS-Related Kaposi's Sarcoma: A Single-Institution Experience. World J Clin Oncol (2013) 4:52. doi: 10.5306/wjco.v4.i2.52

32. Abere B, Li J, Zhou H, Toptan T, Moore PS, Chang Y. Kaposi's SarcomaAssociated Herpesvirus-Encoded circRNAs Are Expressed in Infected Tumor Tissues and Are Incorporated Into Virions. MBio (2020) 11: e03027-19. doi: 10.1128/MBIO.03027-19

33. Tagawa T, Oh D, Santos J, Dremel S, Mahesh G, Uldrick TS, et al. Characterizing Expression and Regulation of Gamma-Herpesviral Circular RNAs. Front Microbiol (2021) 0:670542. doi: 10.3389/ FMICB.2021.670542

34. Rossetto CC, Tarrant-Elorza M, Verma S, Purushothaman P, Pari GS. Regulation of Viral and Cellular Gene Expression by Kaposi's SarcomaAssociated Herpesvirus Polyadenylated Nuclear RNA. J Virol (2013) 87:5540-53. doi: 10.1128/JVI.03111-12

35. Cousins E, Gao Y, Sandford G, Nicholas J. Human Herpesvirus 8 Viral Interleukin-6 Signaling Through Gp130 Promotes Virus Replication in Primary Effusion Lymphoma and Endothelial Cells. J Virol (2014) 88:12167-72. doi: 10.1128/jvi.01751-14

36. Mesri EA, Cesarman E, Boshoff C. Kaposi's Sarcoma and Its Associated Herpesvirus. Nat Rev Cancer (2010) 10:707-19. doi: 10.1038/nrc2888

37. Journo G, Tushinsky C, Shterngas A, Avital N, Eran Y, Karpuj MV, et al. Modulation of Cellular CpG DNA Methylation by Kaposi's SarcomaAssociated Herpesvirus. J Virol (2018) 92:e00008-18. doi: 10.1128/jvi.00008-18

38. Sung HY, Park AK, Ju W, Ahn JH. Overexpression of Mucin 13 Due to Promoter Methylation Promotes Aggressive Behavior in Ovarian Cancer Cells. Yonsei Med J (2014) 55:1206-13. doi: 10.3349/YMJ.2014.55.5.1206

39. Gupta BK, Maher DM, Ebeling MC, Stephenson PD, Puumala SE, Koch MR, et al. Functions and Regulation of MUC13 Mucin in Colon Cancer Cells. J Gastroenterol (2014) 49:1378. doi: 10.1007/S00535-013-0885-Z

40. Xia M, Yao L, Zhang Q, Wang F, Mei H, Guo X, et al. Long Noncoding RNA HOTAIR Promotes Metastasis of Renal Cell Carcinoma by Up-Regulating Histone H3K27 Demethylase JMJD3. Oncotarget (2017) 8:19795. doi: 10.18632/ONCOTARGET.15047

41. Smith CG, Kharkwal H, Wilson DW. Expression and Subcellular Localization of the Kaposi's Sarcoma-Associated Herpesvirus K15P Protein During Latency and Lytic Reactivation in Primary Effusion Lymphoma Cells. J Virol (2017) 91:e01370-17. doi: 10.1128/jvi.01370-17

42. Abere B, Samarina N, Gramolelli S, Rückert J, Gerold G, Pich A, et al. Kaposi's Sarcoma-Associated Herpesvirus Nonstructural Membrane Protein Pk15 Recruits the Class II Phosphatidylinositol 3-Kinase PI3K-C2 $\alpha$ To Activate Productive Viral Replication. J Virol (2018) 92:e00544-18. doi: 10.1128/jvi.00544-18

43. Lauber C, Seitz S, Mattei S, Suh A, Beck J, Herstein J, et al. Deciphering the Origin and Evolution of Hepatitis B Viruses by Means of a Family of NonEnveloped Fish Viruses. Cell Host Microbe (2017) 22:387-99.e6. doi: 10.1016/j.chom.2017.07.019

44. Krause-Kyora B, Susat J, Key FM, Kühnert D, Bosse E, Immel A, et al. Neolithic and Medieval Virus Genomes Reveal Complex Evolution of Hepatitis B. Elife (2018) 7:e36666. doi: 10.7554/eLife.36666
45. Patterson Ross Z, Klunk J, Fornaciari G, Giuffra V, Duchêne S, Duggan AT, et al. The Paradox of HBV Evolution as Revealed From a 16thcentury Mummy. PloS Pathog (2018) 14:e1006750. doi: 10.1371/journal. ppat. 1006750

46. Yang L, Ye S, Zhao X, Ji L, Zhang Y, Zhou P, et al. Molecular Characterization of HBV DNA Integration in Patients With Hepatitis and Hepatocellular Carcinoma. J Cancer (2018) 9:3225-35. doi: 10.7150/ jca. 26052

47. Zhao LH, Liu X, Yan HX, Li WY, Zeng X, Yang Y, et al. Genomic and Oncogenic Preference of HBV Integration in Hepatocellular Carcinoma. Nat Commun (2016) 7:12992. doi: 10.1038/ncomms 12992

48. Xiao Q, Fu B, Chen P, Liu ZZ, Wei W, Ye Q. Three Polymorphisms of Tumor Necrosis Factor-Alpha and Hepatitis B Virus Related Hepatocellular Carcinoma: A Meta-Analysis. Med (United States) (2016) 95:e5609. doi: 10.1097/MD.0000000000005609

49. Wu S, Ye S, Lin X, Chen Y, Zhang Y, Jing Z, et al. Small Hepatitis B Virus Surface Antigen Promotes Malignant Progression of Hepatocellular Carcinoma via Endoplasmic Reticulum Stress-Induced FGF19/JAK2/ STAT3 Signaling. Cancer Lett (2021) 499:175-87. doi: 10.1016/j.canlet. 2020.11.032

50. Tan AT, Yang N, Lee Krishnamoorthy T, Oei V, Chua A, Zhao X, et al. Use of Expression Profiles of HBV-DNA Integrated Into Genomes of Hepatocellular Carcinoma Cells to Select T Cells for Immunotherapy. Gastroenterology (2019) 156:1862-76.e9. doi: 10.1053/j.gastro.2019.01.251

51. Zhang C, Huang C, Sui X, Zhong X, Yang W, Hu X, et al. Association Between Gene Methylation and HBV Infection in Hepatocellular Carcinoma: A Meta-Analysis. J Cancer (2019) 10:6457-65. doi: 10.7150/ jca.33005

52. Zhang Y, Mao R, Yan R, Cai D, Zhang Y, Zhu H, et al. Transcription of Hepatitis B Virus Covalently Closed Circular DNA Is Regulated by CpG Methylation During Chronic Infection. PloS One (2014) 9:e110442. doi: 10.1371/journal.pone.0110442

53. Fitzmaurice C, Akinyemiju T, Abera S, Ahmed M, Alam N, Alemayohu MA, et al. The Burden of Primary Liver Cancer and Underlying Etiologies From 1990 to 2015 at the Global, Regional, and National Level Results From the Global Burden of Disease Study 2015. JAMA Oncol (2017) 3:1683-91. doi: 10.1001/jamaoncol.2017.3055

54. McGlynn KA, Petrick JL, El-Serag HB. Epidemiology of Hepatocellular Carcinoma. Hepatology (2021) 73:4. doi: 10.1002/HEP.31288

55. Chiang CJ, Yang YW, You SL, Lai MS, Chen CJ. Thirty-Year Outcomes of the National Hepatitis B Immunization Program in Taiwan. JAMA (2013) 310:974-6. doi: 10.1001/JAMA.2013.276701

56. Chang MH, You SL, Chen CJ, Liu CJ, Lai MW, Wu TC, et al. Long-Term Effects of Hepatitis B Immunization of Infants in Preventing Liver Cancer. Gastroenterology (2016) 151:472-480.e1. doi: 10.1053/j.gastro.2016.05.048

57. Yu Y, Scheel TKH, Luna JM, Chung H, Nishiuchi E, Scull MA, et al. miRNA Independent Hepacivirus Variants Suggest a Strong Evolutionary Pressure to Maintain miR-122 Dependence. PloS Pathog (2017) 13:e1006694. doi: 10.1371/journal.ppat.1006694

58. Douam F, Fusil F, Enguehard M, Dib L, Nadalin F, Schwaller L, et al. A Protein Coevolution Method Uncovers Critical Features of the Hepatitis C Virus Fusion Mechanism. PloS Pathog (2018) 14:e1006908. doi: 10.1371/ journal.ppat.1006908

59. Tong Y, Lavillette D, Li Q, Zhong J. Role of Hepatitis C Virus Envelope Glycoprotein E1 in Virus Entry and Assembly. Front Immunol (2018) 9:1411. doi: 10.3389/fimmu.2018.01411

60. Rosenberg BR, Depla M, Freije CA, Gaucher D, Mazouz S, Boisvert M, et al. Longitudinal Transcriptomic Characterization of the Immune Response to Acute Hepatitis C Virus Infection in Patients With Spontaneous Viral Clearance. PloS Pathog (2018) 14:e1007290. doi: 10.1371/journal. ppat. 1007290

61. Aydin Y, Kurt R, Song K, Lin D, Osman H, Youngquist B, et al. Hepatic Stress Response in HCV Infection Promotes STAT3-Mediated Inhibition of HNF4A-miR-122 Feedback Loop in Liver Fibrosis and Cancer Progression. Cancers (Basel) (2019) 11:1407. doi: 10.3390/cancers11101407

62. Mileo AM, Mattarocci S, Matarrese P, Anticoli S, Abbruzzese C, Catone S, et al. Hepatitis C Virus Core Protein Modulates Prb2/P130 Expression in Human Hepatocellular Carcinoma Cell Lines Through Promoter 
Methylation. J Exp Clin Cancer Res (2015) 34:140. doi: 10.1186/s13046-0150255-1

63. Sun S, Li Y, Han S, Jia H, Li X, Li X. A Comprehensive Genome-Wide Profiling Comparison Between HBV and HCV Infected Hepatocellular Carcinoma. BMC Med Genomics (2019) 12:147. doi: 10.1186/s12920-0190580-x

64. López-Bueno A, Mavian C, Labella AM, Castro D, Borrego JJ, Alcami A, et al. Concurrence of Iridovirus, Polyomavirus, and a Unique Member of a New Group of Fish Papillomaviruses in Lymphocystis Disease-Affected Gilthead Sea Bream. J Virol (2016) 90:8768-79. doi: 10.1128/JVI.01369-16

65. Steinbach A, Riemer AB. Immune Evasion Mechanisms of Human Papillomavirus: An Update. Int J Cancer (2018) 142:224-9. doi: 10.1002/ ijc.31027

66. Egawa N, Egawa K, Griffin H, Doorbar J. Human Papillomaviruses; Epithelial Tropisms, and the Development of Neoplasia. Viruses (2015) 7:3863-90. doi: 10.3390/v7072802

67. Rojas-Cruz A, Reyes-Bermúdez A. Phylogenetic Analysis of Alphapapillomavirus Based on L1, E6 and E7 Regions Suggests That Carcinogenicity and Tissue Tropism Have Appeared Multiple Times During Viral Evolution. Infect Genet Evol (2019) 67:210-21. doi: 10.1016/ j.meegid.2018.11.008

68. Molet L, Girlich D, Bonnin RA, Proust A, Bouligand J, Bachelerie F, et al. Identification by High-Throughput Sequencing of HPV Variants and Quasispecies That Are Untypeable by Linear Reverse Blotting Assay in Cervical Specimens. Papillomavirus Res (2019) 8:100169. doi: 10.1016/ j.pvr.2019.100169

69. Pal A, Kundu R. Human Papillomavirus E6 and E7: The Cervical Cancer Hallmarks and Targets for Therapy. Front Microbiol (2020) 10:3116. doi: $10.3389 /$ fmicb.2019.03116

70. Tirosh O, Conlan S, Deming C, Lee-Lin S-Q, Huang XNISC Comparative Sequencing Program, et al. Expanded Skin Virome in DOCK8-Deficient Patients. Nat Med (2018) 24:1815-21. doi: 10.1038/s41591-018-0211-7

71. Clarke MA, Gradissimo A, Schiffman M, Lam J, Sollecito CC, Fetterman B, et al. Human Papillomavirus DNA Methylation as a Biomarker for Cervical Precancer: Consistency Across 12 Genotypes and Potential Impact on Management of Hpv-Positive Women. Clin Cancer Res (2018) 24:2194202. doi: 10.1158/1078-0432.CCR-17-3251

72. Serafin-Higuera I, Garibay-Cerdenares OL, Illades-Aguiar B, Flores-Alfaro E, Jiménez-López MA, Sierra-Martínez P, et al. Differential Proteins Among Normal Cervix Cells and Cervical Cancer Cells With HPV-16 Infection, Through Mass Spectrometry-Based Proteomics (2d-DIGE) in Women From Southern México. Proteome Sci (2016) 14:10. doi: 10.1186/s12953-016-0099-4

73. Ludwig S, Marczak L, Sharma P, Abramowicz A, Gawin M, Widlak P, et al. Proteomes of Exosomes From HPV(+) or HPV(-) Head and Neck Cancer Cells: Differential Enrichment in Immunoregulatory Proteins. Oncoimmunology (2019) 8:1593808. doi: 10.1080/2162402X.2019.1593808

74. Harper DM, Franco EL, Wheeler C, Ferris DG, Jenkins D, Schuind A, et al. Efficacy of a Bivalent L1 Virus-Like Particle Vaccine in Prevention of Infection With Human Papillomavirus Types 16 and 18 in Young Women: A Randomised Controlled Trial. Lancet (2004) 364:1757-65. doi: 10.1016/S0140-6736(04)17398-4

75. FUTURE II Study Group. Quadrivalent Vaccine Against Human Papillomavirus to Prevent High-Grade Cervical Lesions. N Engl J Med (2007) 356:1915-27. doi: 10.1056/nejmoa061741

76. Joura EA, Giuliano AR, Iversen O-E, Bouchard C, Mao C, Mehlsen J, et al. A 9-Valent HPV Vaccine Against Infection and Intraepithelial Neoplasia in Women. N Engl J Med (2015) 372:711-23. doi: 10.1056/nejmoa1405044

77. Oakley F, Desouki MM, Pemmaraju M, Gargano JM, Markowitz LE, Steinau M, et al. Trends in High-Grade Cervical Cancer Precursors in the Human Papillomavirus Vaccine Era. Am J Prev Med (2018) 55:19-25. doi: 10.1016/ j.amepre.2018.03.015

78. Rasmussen CL, Thomsen LT, Aalborg GL, Kjaer SK. Incidence of Vulvar High-Grade Precancerous Lesions and Cancer in Denmark Before and After Introduction of HPV Vaccination. Gynecol Oncol (2020) 157:664-70. doi: 10.1016/j.ygyno.2020.03.030

79. Lei J, Ploner A, Elfström KM, Wang J, Roth A, Fang F, et al. HPV Vaccination and the Risk of Invasive Cervical Cancer. N Engl J Med (2020) 383:1340-8. doi: 10.1056/nejmoa1917338
80. Guo F, Cofie LE, Berenson AB. Cervical Cancer Incidence in Young U.S. Females After Human Papillomavirus Vaccine Introduction. Am J Prev Med (2018) 55:197-204. doi: 10.1016/j.amepre.2018.03.013

81. McClung NM, Gargano JW, Bennett NM, Niccolai LM, Abdullah N, Griffin MR, et al. Trends in Human Papillomavirus Vaccine Types 16 and 18 in Cervical Precancers, 2008-2014. Cancer Epidemiol Biomarkers Prev (2019) 28:602-9. doi: 10.1158/1055-9965.EPI-18-0885

82. Tota JE, Struyf F, Merikukka M, Gonzalez P, Kreimer AR, Bi D, et al. Evaluation of Type Replacement Following HPV16/18 Vaccination: Pooled Analysis of Two Randomized Trials. J Natl Cancer Inst (2017) 109:djw300. doi: 10.1093/jnci/djw300

83. Mesher D, Soldan K, Lehtinen M, Beddows S, Brisson M, Brotherton JML, et al. Population-Level Effects of Human Papillomavirus Vaccination Programs on Infections With Nonvaccine Genotypes. Emerg Infect Dis (2016) 22:1732-40. doi: 10.3201/eid2210.160675

84. Man I, Vänskä S, Lehtinen M, Bogaards JA. Human Papillomavirus Genotype Replacement: Still Too Early to Tell? J Infect Dis (2020) 224:481-91. doi: 10.1093/infdis/jiaa032

85. Padgett BL, Zurhein GM, Walker DL, Eckroade RJ, Dessel BH. Cultivation Of Papova-Like Virus From Human Brain With Progressive Multifocal Leucoencephalopathy. Lancet (1971) 297:1257-60. doi: 10.1016/S0140-6736 (71) $91777-6$

86. Gardner SD, Field AM, Coleman DV, Hulme B. New Human Papovavirus (B.K.) Isolated From Urine After Renal Transplantation. Lancet (1971) 297:1253-7. doi: 10.1016/S0140-6736(71)91776-4

87. Buck CB, Van Doorslaer K, Peretti A, Geoghegan EM, Tisza MJ, An P, et al. The Ancient Evolutionary History of Polyomaviruses. PloS Pathog (2016) 12: e1005574. doi: 10.1371/journal.ppat.1005574

88. Torres C. Evolution and Molecular Epidemiology of Polyomaviruses. Infect Genet Evol (2020) 79:104150. doi: 10.1016/j.meegid.2019.104150

89. Shuda M, Feng H, Kwun HJ, Rosen ST, Gjoerup O, Moore PS, et al. T Antigen Mutations Are a Human Tumor-Specific Signature for Merkel Cell Polyomavirus. Proc Natl Acad Sci USA (2008) 105:16272-7. doi: 10.1073/ pnas. 0806526105

90. Verhaegen ME, Mangelberger D, Harms PW, Vozheiko TD, Weick JW, Wilbert DM, et al. Merkel Cell Polyomavirus Small T Antigen Is Oncogenic in Transgenic Mice. J Invest Dermatol (2015) 135:1415-24. doi: 10.1038/ jid.2014.446

91. Borchert S, Czech-Sioli M, Neumann F, Schmidt C, Wimmer P, Dobner T, et al. High-Affinity Rb Binding, P53 Inhibition, Subcellular Localization, and Transformation by Wild-Type or Tumor-Derived Shortened Merkel Cell Polyomavirus Large T Antigens. J Virol (2014) 88:3144-60. doi: 10.1128/ jvi.02916-13

92. Shahzad N, Shuda M, Gheit T, Kwun HJ, Cornet I, Saidj D, et al. The T Antigen Locus of Merkel Cell Polyomavirus Downregulates Human Toll-Like Receptor 9 Expression. J Virol (2013) 87:13009-19. doi: 10.1128/jvi.01786-13

93. Paulson KG, Tegeder A, Willmes C, Iyer JG, Afanasiev OK, Schrama D, et al. Downregulation of MHC-I Expression Is Prevalent But Reversible in Merkel Cell Carcinoma. Cancer Immunol Res (2014) 2:1071-9. doi: 10.1158/23266066.CIR-14-0005

94. Deepa Pantulu N, Pallasch CP, Kurz AK, Kassem A, Frenzel L, Sodenkamp S, et al. Detection of a Novel Truncating Merkel Cell Polyomavirus Large T Antigen Deletion in Chronic Lymphocytic Leukemia Cells. Blood (2010) 116:5280-4. doi: 10.1182/blood-2010-02-269829

95. Ahye N, Bellizzi A, May D, Wollebo HS. The Role of the Jc Virus in Central Nervous System Tumorigenesis. Int J Mol Sci (2020) 21:1-23. doi: 10.3390/ ijms 21176236

96. Rennspiess D, Pujari S, Keijzers M, Abdul-Hamid MA, Hochstenbag M, Dingemans AM, et al. Detection of Human Polyomavirus 7 in Human Thymic Epithelial Tumors. J Thorac Oncol (2015) 10:360-6. doi: 10.1097/ JTO.0000000000000390

97. Worobey M, Telfer P, Souquière S, Hunter M, Coleman CA, Metzger MJ, et al. Island Biogeography Reveals the Deep History of SIV. Science (2010) 329:1487. doi: 10.1126/science.1193550

98. Wang J, Shaban NM, Land AM, Brown WL, Harris RS. Simian Immunodeficiency Virus Vif and Human APOBEC $3 B$ Interactions Resemble Those Between HIV-1 Vif and Human APOBEC3G. $J$ Virol (2018) 92:e00447-18. doi: 10.1128/JVI.00447-18 
99. Plantin J, Massanella M, Chomont N. Inducible HIV RNA Transcription Assays to Measure HIV Persistence: Pros and Cons of a Compromise. Retrovirology (2018) 15:9. doi: 10.1186/s12977-017-0385-y

100. Anderson EM, Maldarelli F. The Role of Integration and Clonal Expansion in HIV Infection: Live Long and Prosper. Retrovirology (2018) 15:71. doi: 10.1186/s12977-018-0448-8

101. Maldarelli F, Wu X, Su L, Simonetti FR, Shao W, Hill S, et al. HIV Latency. Specific HIV Integration Sites Are Linked to Clonal Expansion and Persistence of Infected Cells. Science (2014) 345:179-83. doi: 10.1126/science.1254194

102. Zhang Y, Li SK, Yi Yang K, Liu M, Lee N, Tang X, et al. Whole Genome Methylation Array Reveals the Down-Regulation of IGFBP6 and SATB2 by HIV-1. Sci Rep (2015) 5:10806. doi: 10.1038/srep10806

103. Carrilho C, Miu C, Kim Y, Karki S, Balmaceda A, Challa B, et al. P16 Expression Correlates With Invasive Ocular Surface Squamous Neoplasms in HIV-Infected Mozambicans. Ocul Oncol Pathol (2020) 6:123-8. doi: $10.1159 / 000502096$

104. Li G, Piampongsant S, Faria RN, Voet A, Pineda-Peña AC, Khouri R, et al. An Integrated Map of HIV Genome-Wide Variation From a Population Perspective. Retrovirology (2015) 12:18. doi: 10.1186/s12977-015-0148-6

105. Lyngdoh DL, Shukla H, Sonkar A, Anupam R, Tripathi T. Portrait of the Intrinsically Disordered Side of the HTLV-1 Proteome. ACS Omega (2019) 4:10003-18. doi: 10.1021/acsomega.9b01017

106. Van Dooren S, Salemi M, Vandamme AM. Dating the Origin of the African Human T-Cell Lymphotropic Virus Type-I (HTLV-I) Subtypes. Mol Biol Evol (2001) 18:661-71. doi: 10.1093/oxfordjournals.molbev.a003846

107. Zhang LL, Wei JY, Wang L, Huang S, Chen JL. Human T-Cell Lymphotropic Virus Type 1 and Its Oncogenesis. Acta Pharmacol Sin (2017) 38:1093-103. doi: $10.1038 /$ aps.2017.17

108. Mohanty S, Harhaj EW. Mechanisms of Oncogenesis by HTLV-1 Tax. Pathogens (2020) 9:1-28. doi: 10.3390/PATHOGENS9070543

109. Grassmann R, Aboud M, Jeang KT. Molecular Mechanisms of Cellular Transformation by HTLV-1 Tax. Oncogene (2005) 24:5976-85. doi: 10.1038/ SJ.ONC.1208978

110. Melamed A, Yaguchi H, Miura M, Witkover A, Fitzgerald TW, Birney E, et al. The Human Leukemia Virus HTLV-1 Alters the Structure and Transcription of Host Chromatin in Cis. Elife (2018) 7:e36245. doi: 10.7554/eLife.36245

111. Pise-Masison CA, Mahieux R, Jiang H, Ashcroft M, Radonovich M, Duvall J, et al. Inactivation of P53 by Human T-Cell Lymphotropic Virus Type 1 Tax Requires Activation of the NF- $k b$ Pathway and Is Dependent on P53 Phosphorylation. Mol Cell Biol (2000) 20:3377-86. doi: 10.1128/ mcb.20.10.3377-3386.2000

112. Yeh CH, Bai XT, Moles R, Ratner L, Waldmann TA, Toshiki W, et al. Mutation of Epigenetic Regulators TET2 and MLL3 in Patients With HTLVI-Induced Acute Adult T-Cell Leukemia. Mol Cancer (2016) 15:15. doi: $10.1186 / \mathrm{s} 12943-016-0500-\mathrm{z}$

113. Marçais A, Waast L, Bruneau J, Hanssens K, Asnafi V, Gaulard P, et al. Adult T Cell Leukemia Aggressivenness Correlates With Loss of Both 5Hydroxymethylcytosine and TET2 Expression. Oncotarget (2017) 8:5225668. doi: 10.18632/oncotarget.13665

114. Wolf G, Greenberg D, Macfarlan TS. Spotting the Enemy Within: Targeted Silencing of Foreign DNA in Mammalian Genomes by the KrüppelAssociated Box Zinc Finger Protein Family. Mob DNA (2015) 6:17. doi: $10.1186 / \mathrm{s} 13100-015-0050-8$

115. Ficarelli M, Wilson H, Galão RP, Mazzon M, Antzin-Anduetza I, Marsh M, et al. KHNYN Is Essential for the Zinc Finger Antiviral Protein (ZAP) to Restrict HIV-1 Containing Clustered CpG Dinucleotides. Elife (2019) 8: e46767. doi: 10.7554/eLife.46767

116. Takata MA, Gonçalves-Carneiro D, Zang TM, Soll SJ, York A, Blanco-Melo D, et al. CG Dinucleotide Suppression Enables Antiviral Defence Targeting Non-Self RNA. Nature (2017) 550:124-7. doi: 10.1038/nature24039

117. Younis S, Kamel W, Falkeborn T, Wang H, Yu D, Daniels R, et al. Multiple Nuclear-Replicating Viruses Require the Stress-Induced Protein ZC3H11A for Efficient Growth. Proc Natl Acad Sci USA (2018) 115:E3808-16. doi: 10.1073/pnas.1722333115

118. Hannigan GD, Duhaime MB, Ruffin MT, Koumpouras CC, Schloss PD. Diagnostic Potential and Interactive Dynamics of the Colorectal Cancer Virome. MBio (2018) 9:e2248-18. doi: 10.1128/mBio.02248-18
119. Nakatsu G, Zhou H, Wu WKK, Wong SH, Coker OO, Dai Z, et al. Alterations in Enteric Virome Are Associated With Colorectal Cancer and Survival Outcomes. Gastroenterology (2018) 155:529-41.e5. doi: 10.1053/ j.gastro.2018.04.018

120. Tamarelle J, Thiébaut ACM, de Barbeyrac B, Bébéar C, Ravel J, DelarocqueAstagneau E. The Vaginal Microbiota and Its Association With Human Papillomavirus, Chlamydia Trachomatis, Neisseria Gonorrhoeae and Mycoplasma Genitalium Infections: A Systematic Review and MetaAnalysis. Clin Microbiol Infect (2019) 25:35-47. doi: 10.1016/ j.cmi.2018.04.019

121. Strickley JD, Messerschmidt JL, Awad ME, Li T, Hasegawa T, Ha DT, et al. Immunity to Commensal Papillomaviruses Protects Against Skin Cancer. Nature (2019) 575:519-22. doi: 10.1038/s41586-019-1719-9

122. Hamam R, Hamam D, Alsaleh KA, Kassem M, Zaher W, Alfayez M, et al. Circulating microRNAs in Breast Cancer: Novel Diagnostic and Prognostic Biomarkers. Cell Death Dis (2017) 8:e3045. doi: 10.1038/cddis.2017.440

123. Vojtechova Z, Tachezy R. The Role of miRNAs in Virus-Mediated Oncogenesis. Int J Mol Sci (2018) 19:1217. doi: 10.3390/ijms19041217

124. Gallo A, Miceli V, Bulati M, Iannolo G, Contino F, Conaldi PG, et al. Viral miRNAs as Active Players and Participants in Tumorigenesis. Cancers (Basel) (2020) 12:358. doi: 10.3390/CANCERS12020358

125. Caetano BFR, Jorge BAS, Müller-Coan BG, Elgui de Oliveira D. Epstein-Barr Virus microRNAs in the Pathogenesis of Human Cancers. Cancer Lett (2021) 499:14-23. doi: 10.1016/J.CANLET.2020.11.019

126. Movassagh M, Oduor C, Forconi C, Moormann AM, Bailey JA. Sensitive Detection of EBV microRNAs Across Cancer Spectrum Reveals Association With Decreased Survival in Adult Acute Myelocytic Leukemia. Sci Rep 2019 91 (2019) 9:1-10. doi: 10.1038/s41598-019-56472-1

127. Vereide DT, Seto E, Chiu Y-F, Hayes M, Tagawa T, Grundhoff A, et al. Epstein-Barr Virus Maintains Lymphomas via Its miRNAs. Oncogene (2014) 33:1258. doi: 10.1038/ONC.2013.71

128. Ambrosio MR, Navari M, Lisio L, Leon EA, Onnis A, Gazaneo S, et al. The Epstein Barr-Encoded BART-6-3p microRNA Affects Regulation of Cell Growth and Immuno Response in Burkitt Lymphoma. Infect Agent Cancer (2014) 9:12. doi: 10.1186/1750-9378-9-12

129. Li Z, Chen X, Li L, Liu S, Yang L, Ma X, et al. EBV Encoded miR-BHRF1-1 Potentiates Viral Lytic Replication by Downregulating Host P53 in Nasopharyngeal Carcinoma. Int J Biochem Cell Biol (2012) 44:275-9. doi: 10.1016/J.BIOCEL.2011.11.007

130. Zheng X, Wang J, Wei L, Peng Q, Gao Y, Fu Y, et al. Epstein-Barr Virus MicroRNA miR-BART5-3p Inhibits P53 Expression. J Virol (2018) 92: e01022-18. doi: 10.1128/JVI.01022-18

131. Cheung CCM, Chung GTY, Lun SWM, To KF, Choy KW, Lau KM, et al. miR-31 Is Consistently Inactivated in EBV-Associated Nasopharyngeal Carcinoma and Contributes to Its Tumorigenesis. Mol Cancer (2014) 13:184. doi: 10.1186/1476-4598-13-184

132. Ungerleider N, Bullard W, Kara M, Wang X, Roberts C, Renne R, et al. EBV miRNAs Are Potent Effectors of Tumor Cell Transcriptome Remodeling in Promoting Immune Escape. PloS Pathog (2021) 17:e1009217. doi: 10.1371/ JOURNAL.PPAT.1009217

133. Liu Q, Shuai M, Xia Y. Knockdown of EBV-Encoded circRNA Circrpms1 Suppresses Nasopharyngeal Carcinoma Cell Proliferation and Metastasis Through Sponging Multiple miRNAs. Cancer Manag Res (2019) 11:8023-31. doi: 10.2147/CMAR.S218967

134. Walz N, Christalla T, Tessmer U, Grundhoff A. A Global Analysis of Evolutionary Conservation Among Known and Predicted Gammaherpesvirus MicroRNAs. J Virol (2010) 84:716. doi: 10.1128/ JVI.01302-09

135. Viollet C, Davis DA, Reczko M, Ziegelbauer JM, Pezzella F, Ragoussis J, et al. Next-Generation Sequencing Analysis Reveals Differential Expression Profiles of MiRNA-mRNA Target Pairs in KSHV-Infected Cells. PloS One (2015) 10:e0126439. doi: 10.1371/JOURNAL.PONE.0126439

136. Viollet C, Davis DA, Tekeste SS, Reczko M, Ziegelbauer JM, Pezzella F, et al. RNA Sequencing Reveals That Kaposi Sarcoma-Associated Herpesvirus Infection Mimics Hypoxia Gene Expression Signature. PloS Pathog (2017) 13:e1006143. doi: 10.1371/JOURNAL.PPAT.1006143

137. Morrison K, Manzano M, Chung K, Schipma MJ, Bartom ET, Gottwein E. The Oncogenic Kaposi's Sarcoma-Associated Herpesvirus Encodes a Mimic 
of the Tumor-Suppressive miR-15/16 miRNA Family. Cell Rep (2019) 29:2961-9.e6. doi: 10.1016/J.CELREP.2019.11.005

138. Yang X, Li H, Sun H, Fan H, Hu Y, Liu M, et al. Hepatitis B Virus-Encoded MicroRNA Controls Viral Replication. J Virol (2017) 91:e01919-16. doi: 10.1128/JVI.01919-16

139. Tang J, Xiao XQ, Jiang Y, Tian Y, Peng Z, Yang M, et al. miR-3 Encoded by Hepatitis B Virus Downregulates PTEN Protein Expression and Promotes Cell Proliferation. J Hepatocell Carcinoma (2020) 7:257-69. doi: 10.2147/ JHC.S271091

140. Dai X, Huang R, Hu S, Zhou Y, Sun X, Gui P, et al. A Novel miR-0308-3p Revealed by miRNA-Seq of HBV-Positive Hepatocellular Carcinoma Suppresses Cell Proliferation and Promotes G1/S Arrest by Targeting Double CDK6/Cyclin D1 Genes. Cell Biosci 2020101 (2020) 10:1-18. doi: 10.1186/S13578-020-00382-7

141. Chen Y, Chen J, Wang H, Shi J, Wu K, Liu S, et al. HCV-Induced miR-21 Contributes to Evasion of Host Immune System by Targeting MyD88 and IRAK1. PloS Pathog (2013) 9(4):e1003248. doi: 10.1371/JOURNAL.PPAT. 1003248

142. Li C, Lu L, Qi Z, Zhu Y, Su F, Zhao P, et al. Transcriptome and Mirnome Analysis Provide New Insight Into Host Lipid Accumulation, Innate Immunity, and Viral Persistence in Hepatitis C Virus Infection In Vitro. Front Microbiol (2020) 11:535673. doi: 10.3389/FMICB.2020.535673

143. Božinović K, Sabol I, Dediol E, Milutin Gašperov N, Manojlović S, Vojtechova Z, et al. Genome-Wide miRNA Profiling Reinforces the Importance of miR-9 in Human Papillomavirus Associated Oral and Oropharyngeal Head and Neck Cancer. Sci Rep (2019) 9:1-13. doi: 10.1038/s41598-019-38797-z

144. Snoek BC, Verlaat W, Babion I, Novianti PW, de Wiel MAv, Wilting SM, et al. Genome-Wide microRNA Analysis of HPV-Positive Self-Samples Yields Novel Triage Markers for Early Detection of Cervical Cancer. Int $J$ Cancer (2019) 144:372. doi: 10.1002/IJC.31855

145. Qian K, Pietilä T, Rönty M, Michon F, Frilander MJ, Ritari J, et al. Identification and Validation of Human Papillomavirus Encoded microRNAs. PloS One (2013) 8:e70202. doi: 10.1371/JOURNAL.PONE. 0070202

146. Gutiérrez DA, Varela-Ramírez A, Rodríguez-Esquivel M, MendozaRodrígueze MG, Ayala-Sumuanoe JT, Pineda D, et al. Predicting Human miRNA-Like Sequences Within Human Papillomavirus Genomes. Arch Med Res (2018) 49:323-34. doi: 10.1016/J.ARCMED.2018.10.008

147. Chen CJ, Cox JE, Azarm KD, Wylie KN, Woolard KD, Pesavento PA, et al. Identification of a Polyomavirus microRNA Highly Expressed in Tumors. Virology (2015) 476:43-53. doi: 10.1016/J.VIROL.2014.11.021

148. Fan K, Spassova I, Gravemeyer J, Ritter C, Horny K, Lange A, et al. Merkel Cell Carcinoma-Derived Exosome-Shuttle miR-375 Induces Fibroblast Polarization by Inhibition of RBPJ and P53. Oncogene (2020) 40:980-96. doi: 10.1038/s41388-020-01576-6

149. Luzzi A, Morettini F, Gazaneo S, Mundo L, Onnis A, Mannucci S, et al. HIV1 Tat Induces DNMT Over-Expression Through microRNA Dysregulation in HIV-Related Non Hodgkin Lymphomas. Infect Agents Cancer (2014) 9:118. doi: 10.1186/1750-9378-9-41

150. Ghobadi MZ, Emamzadeh R, Mozhgani S-H. Deciphering microRNAmRNA Regulatory Network in Adult T-Cell Leukemia/Lymphoma; the Battle Between Oncogenes and Anti-Oncogenes. PloS One (2021) 16: e0247713. doi: 10.1371/JOURNAL.PONE.0247713

151. Hermeking H. The miR-34 Family in Cancer and Apoptosis. Cell Death Differ (2010) 17:193-9. doi: 10.1038/CDD.2009.56

152. Sharma VK, Raimondi V, Ruggero K, Pise-Masison CA, Cavallari I, SilicBenussi M, et al. Expression of miR-34a in T-Cells Infected by Human TLymphotropic Virus 1. Front Microbiol (2018) 9:832. doi: 10.3389/ FMICB.2018.00832

153. Valadão de Souza DR, Pessôa R, Nascimento A, Nukui Y, Pereira J, Casseb J, et al. Small RNA Profiles of HTLV-1 Asymptomatic Carriers With Monoclonal and Polyclonal Rearrangement of the T-cell Antigen Receptor $\gamma$-Chain Using Massively Parallel Sequencing: A Pilot Study. Oncol Lett (2020) 20:2311-21. doi: 10.3892/OL.2020.11803

154. Griffiths DJ. Endogenous Retroviruses in the Human Genome Sequence. Genome Biol (2001) 2:REVIEWS1017. doi: 10.1186/gb-2001-2-6reviews1017
155. Aiewsakun P, Katzourakis A. Marine Origin of Retroviruses in the Early Palaeozoic Era. Nat Commun (2017) 8:13954. doi: 10.1038/ncomms13954

156. Geis FK, Goff SP. Silencing and Transcriptional Regulation of Endogenous Retroviruses: An Overview. Viruses (2020) 12:884. doi: 10.3390/v12080884

157. Ito J, Sugimoto R, Nakaoka H, Yamada S, Kimura T, Hayano T, et al. Systematic Identification and Characterization of Regulatory Elements Derived From Human Endogenous Retroviruses. PloS Genet (2017) 13: e1006883. doi: 10.1371/journal.pgen.1006883

158. Cornelis G, Funk M, Vernochet C, Leal F, Tarazona OA, Meurice G, et al. An Endogenous Retroviral Envelope Syncytin and Its Cognate Receptor Identified in the Viviparous Placental Mabuya Lizard. Proc Natl Acad Sci USA (2017) 114:E10991-11000. doi: 10.1073/pnas.1714590114

159. Magiorkinis G, Gifford RJ, Katzourakis A, De Ranter J, Belshaw R. Env-Less Endogenous Retroviruses Are Genomic Superspreaders. Proc Natl Acad Sci USA (2012) 109:7385-90. doi: 10.1073/pnas.1200913109

160. Bergallo M, Marozio L, Botta G, Tancredi A, Daprà V, Galliano I, et al. Human Endogenous Retroviruses Are Preferentially Expressed in Mononuclear Cells From Cord Blood Than From Maternal Blood and in the Fetal Part of Placenta. Front Pediatr (2020) 8:244. doi: 10.3389/fped.2020.00244

161. Esnault C, Priet S, Ribet D, Vernochet C, Bruls T, Lavialle C, et al. A Placenta-Specific Receptor for the Fusogenic, Endogenous RetrovirusDerived, Human Syncytin-2. Proc Natl Acad Sci (2008) 105:17532-7. doi: 10.1073/PNAS.0807413105

162. Denner J. Expression and Function of Endogenous Retroviruses in the Placenta. APMIS (2016) 124:31-43. doi: 10.1111/APM.12474

163. Ruebner M, Strissel PL, Ekici AB, Stiegler E, Dammer U, Goecke TW, et al. Reduced Syncytin-1 Expression Levels in Placental Syndromes Correlates With Epigenetic Hypermethylation of the ERVW-1 Promoter Region. PloS One (2013) 8:e56145. doi: 10.1371/journal.pone.0056145

164. Tug E, Yirmibes Karaoguz M, Nas T. Expression of the Syncytin-1 and Syncytin-2 Genes in the Trophoblastic Tissue of the Early Pregnancy Losses With Normal and Abnormal Karyotypes. Gene (2020) 741:144533. doi: 10.1016/J.GENE.2020.144533

165. Sugimoto J, Sugimoto M, Bernstein H, Jinno Y, Schust D. A Novel Human Endogenous Retroviral Protein Inhibits Cell-Cell Fusion. Sci Rep (2013) 3:1462. doi: 10.1038/SREP01462

166. Sugimoto J, Schust DJ, Kinjo T, Aoki Y, Jinno Y, Kudo Y. Suppressyn Localization and Dynamic Expression Patterns in Primary Human Tissues Support a Physiologic Role in Human Placentation. Sci Rep (2019) 9:19502. doi: 10.1038/S41598-019-55933-X

167. Augusto DG, Norman PJ, Dandekar R, Hollenbach JA. Fluctuating and Geographically Specific Selection Characterize Rapid Evolution of the Human Kir Region. Front Immunol (2019) 10:989. doi: 10.3389/ fimmu.2019.00989

168. Chuong EB. The Placenta Goes Viral: Retroviruses Control Gene Expression in Pregnancy. PloS Biol (2018) 16:e3000028. doi: 10.1371/journal. pbio. 3000028

169. Moffett A, Loke YW. The Immunological Paradox of Pregnancy: A Reappraisal. Placenta (2004) 25:1-8. doi: 10.1016/S0143-4004(03)00167-X

170. Silasi M, Cardenas I, Kwon J-Y, Racicot K, Aldo P, Mor G. Viral Infections During Pregnancy. Am J Reprod Immunol (2015) 73:199-213. doi: 10.1111/ aji. 12355

171. Grow EJ, Flynn RA, Chavez SL, Bayless NL, Wossidlo M, Wesche DJ, et al. Intrinsic Retroviral Reactivation in Human Preimplantation Embryos and Pluripotent Cells. Nature (2015) 522:221-46. doi: 10.1038/nature14308

172. Agoni L, Guha C, Lenz J. Detection of Human Endogenous Retrovirus K (HERV-K) Transcripts in Human Prostate Cancer Cell Lines. Front Oncol (2013) 3:180. doi: 10.3389/fonc.2013.00180

173. Matysiak J, Lesbats P, Mauro E, Lapaillerie D, Dupuy J-W, Lopez AP, et al. Modulation of Chromatin Structure by the FACT Histone Chaperone Complex Regulates HIV-1 Integration. Retrovirology (2017) 14:39. doi: 10.1186/s12977-017-0363-4

174. Gonzalez-Hernandez MJ, Swanson MD, Contreras-Galindo R, Cookinham S, King SR, Noel RJ, et al. Expression of Human Endogenous Retrovirus Type K (HML-2) Is Activated by the Tat Protein of HIV-1. J Virol (2012) 86:7790805. doi: 10.1128/JVI.07215-11

175. Young GR, Terry SN, Manganaro L, Cuesta-Dominguez A, Deikus G, Bernal-Rubio D, et al. HIV-1 Infection of Primary CD4+ T Cells Regulates 
the Expression of Specific Human Endogenous Retrovirus HERV-K (HML-2) Elements. J Virol (2018) 92:e01507-17. doi: 10.1128/JVI.01507-17

176. Uleri E, Mei A, Mameli G, Poddighe L, Serra C, Dolei A. HIV Tat Acts on Endogenous Retroviruses of the W Family and This Occurs via Toll-Like Receptor 4: Inference for neuroAIDS. AIDS (2014) 28:2659-70. doi: 10.1097/ QAD.0000000000000477

177. Terry SN, Manganaro L, Cuesta-Dominguez A, Brinzevich D, Simon V, Mulder LCF. Expression of HERV-K108 Envelope Interferes With HIV-1 Production. Virology (2017) 509:52-9. doi: 10.1016/j.virol.2017.06.004

178. Brinzevich D, Young GR, Sebra R, Ayllon J, Maio SM, Deikus G, et al. HIV-1 Interacts With Human Endogenous Retrovirus K (HML-2) Envelopes Derived From Human Primary Lymphocytes. J Virol (2014) 88:6213-23. doi: 10.1128/jvi.00669-14

179. Michaud HA, de Mulder M, SenGupta D, Deeks SG, Martin JN, Pilcher CD, et al. Trans-Activation, Post-Transcriptional Maturation, and Induction of Antibodies to HERV-K (HML-2) Envelope Transmembrane Protein in HIV1 Infection. Retrovirology (2014) 11:10. doi: 10.1186/1742-4690-11-10

180. Dai L, Del Valle L, Miley W, Whitby D, Ochoa AC, Flemington EK, et al. Transactivation of Human Endogenous Retrovirus K (HERV-K) by KSHV Promotes Kaposi's Sarcoma Development. Oncogene (2018) 37:4534-45. doi: 10.1038/s41388-018-0282-4

181. Hsiao FC, Tai AK, Deglon A, Sutkowski N, Longnecker R, Huber BT. EBV LMP-2A Employs a Novel Mechanism to Transactivate the HERV-K18 Superantigen Through Its ITAM. Virology (2009) 385:261-6. doi: 10.1016/ j.virol.2008.11.025

182. Mameli G, Poddighe L, Mei A, Uleri E, Sotgiu S, Serra C, et al. Expression and Activation by Epstein Barr Virus of Human Endogenous RetrovirusesW in Blood Cells and Astrocytes: Inference for Multiple Sclerosis. PloS One (2012) 7:e44991. doi: 10.1371/journal.pone.0044991

183. Leung A, Trac C, Kato H, Costello KR, Chen Z, Natarajan R, et al. LTRs Activated by Epstein-Barr Virus-Induced Transformation of B Cells Alter the Transcriptome. Genome Res (2018) 28:1791-8. doi: 10.1101/ gr.233585.117

184. Liu C, Liu L, Wang X, Liu Y, Wang M, Zhu F. HBV X Protein Induces Overexpression of HERV-W Env Through NF- $\mathrm{kb}$ in HepG2 Cells. Virus Genes (2017) 53:797-806. doi: 10.1007/s11262-017-1479-2

185. Toufaily C, Landry S, Leib-Mosch C, Rassart E, Barbeau B. Activation of LTRs From Different Human Endogenous Retrovirus (HERV) Families by the HTLV-1 Tax Protein and T-Cell Activators. Viruses (2011) 3:2146-59. doi: $10.3390 / \mathrm{v} 3112146$

186. Magiorkinis G, Blanco-Melo D, Belshaw R. The Decline of Human Endogenous Retroviruses: Extinction and Survival. Retrovirology (2015) 12:8. doi: 10.1186/s12977-015-0136-x

187. Katzourakis A, Magiorkinis G, Lim AG, Gupta S, Belshaw R, Gifford R. Larger Mammalian Body Size Leads to Lower Retroviral Activity. PloS Pathog (2014) 10:e1004214. doi: 10.1371/journal.ppat.1004214

188. Dolei A, Ibba G, Piu C, Serra C. Expression of HERV Genes as Possible Biomarker and Target in Neurodegenerative Diseases. Int J Mol Sci (2019) 20:3706. doi: 10.3390/ijms20153706

189. Huang CL, Leblond AL, Turner EC, Kumar AH, Martin K, Whelan D, et al. Synthetic Chemically Modified mRNA-Based Delivery of Cytoprotective Factor Promotes Early Cardiomyocyte Survival Post-Acute Myocardial Infarction. Mol Pharm (2015) 12:991-6. doi: 10.1021/mp5006239

190. Steichen C, Luce E, Maluenda J, Tosca L, Moreno-Gimeno I, Desterke C, et al. Messenger RNA- Versus Retrovirus-Based Induced Pluripotent Stem Cell Reprogramming Strategies: Analysis of Genomic Integrity. Stem Cells Transl Med (2014) 3:686-91. doi: 10.5966/sctm.2013-0158

191. Ohnuki M, Tanabe K, Sutou K, Teramoto I, Sawamura Y, Narita M, et al. Dynamic Regulation of Human Endogenous Retroviruses Mediates FactorInduced Reprogramming and Differentiation Potential. Proc Natl Acad Sci USA (2014) 111:12426-31. doi: 10.1073/pnas.1413299111

192. Thekkeparambil Chandrabose S, Sriram S, Subramanian S, Cheng S, Ong WK, Rozen S, et al. Amenable Epigenetic Traits of Dental Pulp Stem Cells Underlie High Capability of Xeno-Free Episomal Reprogramming. Stem Cell Res Ther (2018) 9:68. doi: 10.1186/s13287-018-0796-2

193. Batlle E, Clevers H. Cancer Stem Cells Revisited. Nat Med (2017) 23:112434. doi: $10.1038 / \mathrm{nm} .4409$
194. Díaz-Carballo D, Acikelli AH, Klein J, Jastrow H, Dammann P, Wyganowski T, et al. Therapeutic Potential of Antiviral Drugs Targeting Chemorefractory Colorectal Adenocarcinoma Cells Overexpressing Endogenous Retroviral Elements. J Exp Clin Cancer Res (2015) 34:81. doi: 10.1186/s13046-015-0199-5

195. Zhang Y, Li T, Preissl S, Amaral ML, Grinstein JD, Farah EN, et al. Transcriptionally Active HERV-H Retrotransposons Demarcate Topologically Associating Domains in Human Pluripotent Stem Cells. Nat Genet (2019) 51:1380-8. doi: 10.1038/s41588-019-0479-7

196. Valton AL, Dekker J. TAD Disruption as Oncogenic Driver. Curr Opin Genet Dev (2016) 36:34-40. doi: 10.1016/j.gde.2016.03.008

197. Gong Y, Lazaris C, Sakellaropoulos T, Lozano A, Kambadur P, Ntziachristos $\mathrm{P}$, et al. Stratification of TAD Boundaries Reveals Preferential Insulation of Super-Enhancers by Strong Boundaries. Nat Commun (2018) 9:542. doi: 10.1038/s41467-018-03017-1

198. Grandi N, Tramontano E. Human Endogenous Retroviruses Are Ancient Acquired Elements Still Shaping Innate Immune Responses. Front Immunol (2018) 9:2039. doi: 10.3389/fimmu.2018.02039

199. Liu C, Xu J, Wen F, Yang F, Li X, Geng D, et al. Upregulation of Syncytin-1 Promotes Invasion and Metastasis by Activating Epithelial-Mesenchymal Transition-Related Pathway in Endometrial Carcinoma. Onco Targets Ther (2019) 12:31-40. doi: 10.2147/OTT.S191041

200. Argaw-Denboba A, Balestrieri E, Serafino A, Cipriani C, Bucci I, Sorrentino R, et al. HERV-K Activation Is Strictly Required to Sustain CD133+ Melanoma Cells With Stemness Features. J Exp Clin Cancer Res (2017) 36:20. doi: 10.1186/s13046-016-0485-x

201. Kassiotis G. Endogenous Retroviruses and the Development of Cancer. J Immunol (2014) 192:1343-9. doi: 10.4049/jimmunol.1302972

202. Buzdin A, Kovalskaya-Alexandrova E, Gogvadze E, Sverdlov E. At Least 50\% of Human-Specific HERV-K (HML-2) Long Terminal Repeats Serve In Vivo as Active Promoters for Host Nonrepetitive DNA Transcription. J Virol (2006) 80:10752-62. doi: 10.1128/JVI.00871-06

203. Nikitin D, Penzar D, Garazha A, Sorokin M, Tkachev V, Borisov N, et al. Profiling of Human Molecular Pathways Affected by Retrotransposons at the Level of Regulation by Transcription Factor Proteins. Front Immunol (2018) 9:30. doi: 10.3389/fimmu.2018.00030

204. Thompson PJ, Macfarlan TS, Lorincz MC. Long Terminal Repeats: From Parasitic Elements to Building Blocks of the Transcriptional Regulatory Repertoire. Mol Cell (2016) 62:766-76. doi: 10.1016/j.molcel.2016.03.029

205. Wang T, Zeng J, Lowe CB, Sellers RG, Salama SR, Yang M, et al. SpeciesSpecific Endogenous Retroviruses Shape the Transcriptional Network of the Human Tumor Suppressor Protein P53. Proc Natl Acad Sci USA (2007) 104:18613-8. doi: 10.1073/pnas.0703637104

206. Hurst TP, Aswad A, Karamitros T, Katzourakis A, Smith AL, Magiorkinis G. Interferon-Inducible Protein 16 (IFI16) has a Broad-Spectrum Binding Ability Against Ss DNA Targets: An Evolutionary Hypothesis for Antiretroviral Checkpoint. Front Microbiol (2019) 10:1426. doi: 10.3389/ fmicb.2019.01426

207. Natoli M, Gallon J, Lu H, Amgheib A, Pinato DJ, Mauri FA, et al. Transcriptional Analysis of Multiple Ovarian Cancer Cohorts Reveals Prognostic and Immunomodulatory Consequences of ERV Expression. J Immunother Cancer (2021) 9:e001519. doi: 10.1136/jitc-2020-001519

208. Nakagawa S, Kawashima M, Miyatake Y, Kudo K, Kotaki R, Ando K, et al. Expression of ERV3-1 in Leukocytes of Acute Myelogenous Leukemia Patients. Gene (2021) 773:145363. doi: 10.1016/j.gene.2020.145363

209. de Oliveira RTG, Cordeiro JVA, Vitoriano BF, de Lima Melo MM, Sampaio LR, de Paula Borges D, et al. ERVs-TLR3-IRF Axis Is Linked to Myelodysplastic Syndrome Pathogenesis. Med Oncol (2021) 38:27. doi: 10.1007/s12032-021-01466-1

210. Issa ME, Takhsha FS, Chirumamilla CS, Perez-Novo C, Vanden Berghe W, Cuendet M. Epigenetic Strategies to Reverse Drug Resistance in Heterogeneous Multiple Myeloma. Clin Epigenet (2017) 9:17. doi: 10.1186/ s13148-017-0319-5

211. Ishiguro K, Kitajima $H$, Niinuma T, Maruyama R, Nishiyama N, Ohtani H, et al. Dual EZH2 and G9a Inhibition Suppresses Multiple Myeloma Cell Proliferation by Regulating the Interferon Signal and IRF4-MYC Axis. Cell Death Discov (2021) 7:7. doi: 10.1038/s41420-020-00400-0 
212. Lemaître C, Tsang J, Bireau C, Heidmann T, Dewannieux M. A Human Endogenous Retrovirus-Derived Gene That can Contribute to Oncogenesis by Activating the ERK Pathway and Inducing Migration and Invasion. PloS Pathog (2017) 13:e1006451. doi: 10.1371/journal.ppat.1006451

213. Wang-Johanning F, Li M, Esteva FJ, Hess KR, Yin B, Rycaj K, et al. Human Endogenous Retrovirus Type K Antibodies and mRNA as Serum Biomarkers of Early-Stage Breast Cancer. Int J Cancer (2014) 134:587-95. doi: 10.1002/ ijc. 28389

214. Curty G, Beckerle GA, Iñiguez LP, Furler RL, de Carvalho PS, Marston JL, et al. Human Endogenous Retrovirus Expression Is Upregulated in the Breast Cancer Microenvironment of HIV Infected Women: A Pilot Study. Front Oncol (2020) 10:553983. doi: 10.3389/fonc.2020.553983

215. Kahyo T, Tao H, Shinmura K, Yamada H, Mori H, Funai K, et al. Identification and Association Study With Lung Cancer for Novel Insertion Polymorphisms of Human Endogenous Retrovirus. Carcinogenesis (2013) 34:2531-8. doi: 10.1093/carcin/bgt253

216. Cai HZ, Zhang H, Yang J, Zeng J, Wang H. Preliminary Assessment of Viral Metagenome From Cancer Tissue and Blood From Patients With Lung Adenocarcinoma. J Med Virol (2021) 93:5126-33. doi: 10.1002/jmv.26887

217. Golkaram M, Salmans ML, Kaplan S, Vijayaraghavan R, Martins M, Khan N, et al. HERVs Establish a Distinct Molecular Subtype in Stage II/III Colorectal Cancer With Poor Outcome. NPJ Genomic Med (2021) 6:13. doi: 10.1038/ s41525-021-00177-w

218. Katoh I, Mírová A, Kurata Si, Murakami Y, Horikawa K, Nakakuki N, et al. Activation of the Long Terminal Repeat of Human Endogenous Retrovirus K by Melanoma-Specific Transcription Factor MITF-M. Neoplasia (2011) 13:1081-92. doi: 10.1593/neo.11794

219. Singh M, Cai H, Bunse M, Feschotte C, Izsvák Z. Human Endogenous Retrovirus K Rec Forms a Regulatory Loop With MITF That Opposes the Progression of Melanoma to an Invasive Stage. Viruses (2020) 12:1303. doi: $10.3390 / \mathrm{v} 12111303$

220. Chan SM, Sapir T, Park S-S, Rual J-F, Contreras-Galindo R, Reiner O, et al. The HERV-K Accessory Protein Np9 Controls Viability and Migration of
Teratocarcinoma Cells. PloS One (2019) 14:e0212970. doi: 10.1371/ journal.pone.0212970

221. Takahashi Y, Harashima N, Kajigaya S, Yokoyama H, Cherkasova E, McCoy JP, et al. Regression of Human Kidney Cancer Following Allogeneic Stem Cell Transplantation Is Associated With Recognition of an HERV-E Antigen by T Cells. J Clin Invest (2008) 118:1099. doi: 10.1172/ JCI34409

222. Cherkasova E, Scrivani C, Doh S, Weisman Q, Takahashi Y, Harashima N, et al. Detection of an Immunogenic HERV-E Envelope With Selective Expression in Clear Cell Kidney Cancer. Cancer Res (2016) 76:2177-85. doi: 10.1158/0008-5472.CAN-15-3139

223. Smith CC, Beckermann KE, Bortone DS, Cubas AA, Bixby LM, Lee SJ, et al. Endogenous Retroviral Signatures Predict Immunotherapy Response in Clear Cell Renal Cell Carcinoma. J Clin Invest (2018) 128:4804-20. doi: 10.1172/JCI121476

Conflict of Interest: The authors declare that the research was conducted in the absence of any commercial or financial relationships that could be construed as a potential conflict of interest.

Publisher's Note: All claims expressed in this article are solely those of the authors and do not necessarily represent those of their affiliated organizations, or those of the publisher, the editors and the reviewers. Any product that may be evaluated in this article, or claim that may be made by its manufacturer, is not guaranteed or endorsed by the publisher.

Copyright (c) 2021 Kitsou, Iliopoulou, Spoulou, Lagiou and Magiorkinis. This is an open-access article distributed under the terms of the Creative Commons Attribution License (CC BY). The use, distribution or reproduction in other forums is permitted, provided the original author(s) and the copyright owner(s) are credited and that the original publication in this journal is cited, in accordance with accepted academic practice. No use, distribution or reproduction is permitted which does not comply with these terms. 